\title{
A Modified ACO with K-OPT for Restricted Covering Salesman Problems in Different Environments
}

Prasanta Dutta ( $\nabla$ dutta1900@yahoo.com )

Debra Thana S.K.S Mahavidyalaya

Indadul Khan

Chandrakona Vidyasagar MV https://orcid.org/0000-0002-4052-551X

Krishnendu Basuli

West Bengal State University

Manas Kumar Maiti

Mahishadal Raj College

\section{Research Article}

Keywords: Covering Salesmen Problem, Ant Colony Optimization, K-opt operation, Fuzzy Simulation, Rough Simulation

Posted Date: January 10th, 2022

DOI: https://doi.org/10.21203/rs.3.rs-1060695/v1

License: (1) (1) This work is licensed under a Creative Commons Attribution 4.0 International License. Read Full License

Version of Record: A version of this preprint was published at Soft Computing on April 8th, 2022. See the published version at https://doi.org/10.1007/s00500-022-06978-0. 


\title{
A MODIFIED ACO WITH K-OPT FOR RESTRICTED COVERING SALESMAN PROBLEMS IN DIFFERENT ENVIRONMENTS
}

\begin{abstract}
In this study, the ant colony optimization (ACO) algorithm is modified with the K-opt operation to solve the covering salesman problem(CSP) under one restriction in crisp and imprecise (fuzzy, rough) environments. A CSP involves two phases- the division of cities into groups with the selection of the visiting cities and searching of the Hamiltonian circuit through the visiting cities. But, none of the studies in the literature is made following the direct approach. Also, none of the studies in the literature gives attention to reduce the total travel distance of the unvisited cities from the visited city of a group. Moreover, there is no algorithm in the literature which provides the solution of a CSP with the specified coverage range $r$. Also, none has introduced any algorithm to solve CSPs in imprecise environments. Though algorithms are available to solve the Traveling Salesman Problems in the imprecise environments, the approach cannot deal with the problems involving fuzzy data with non-linear membership functions or the problems involving rough data where the rough estimation can not be done using Lebesgue measure. The well establish algorithm for any routing problem is the ACO, but not much attention has been paid to solve the CSP using ACOs. To overcome these limitations on the studies of the ACO on the CSPs, here, an algorithm is proposed for the division of groups of the set of cities depending upon the maximum number of cities in a group and the total number of groups. Then ACO is used to find the shortest/minimum-cost path of the problem by selecting only one visiting the city from each group without violating the restriction of the specified coverage range $r$ of the location of the unvisited cities. K-opt operation is applied periodically at the end of ACO operation to improve the quality of the best found solution so far by the ACO algorithm and to arrest any premature convergence. For the restricted problems paths are searched in such a manner that the total distance/travel cost of different unvisited cities of a group from the visited city of the group should not exceed a predefined upper limit. To solve the problem in an imprecise environment some approach is followed so that the tour is searched without transferring the imprecise optimisation problem into an equivalent crisp optimisation problem. Also, the simulation approaches in fuzzy and rough environments are proposed to deal with the CSPs with any type of estimation of the imprecise data set. Algorithm is tested with the standard benchmark crisp problems available in the literature. To test the algorithm in the imprecise environments, the imprecise instances are derived randomly from the standard crisp instances using a specified rule. Test results imply that the proposed algorithm is efficient enough in solving the CSPs in the crisp as well as in the imprecise environments.
\end{abstract}

Keywords: Covering Salesmen Problem; Ant Colony Optimization; K-opt operation; Fuzzy Simulation; Rough Simulation.

\section{INTRODUCTION}

A covering salesman problem (CSP) is a complete weighted graph, consists of a set of vertices, called cities, and a weight matrix, called distance (cost) matrix which consists of the distance (travelling cost) between any two cities. The goal of the problem is to find the different clusters (groups) of the cities and then find a minimum cost Hamiltonian circuit visiting only one city in each cluster so that each unvisited city in a cluster should be located in a predefined coverage range of the visiting city. A maximum number of cities in a group is provided in the problem. The clustering and the searching of Hamiltonian circuit is made in such a manner that the travelling distance (cost) through the circuit is a minimum. The CSP has various real life applications, like, telecommunication [14], health care [9], disaster management[21], humanitarian relief[2], transportation[28], etc. For the relief of effected areas of different natural disasters, like, 
flood, earthquake, tsunami, etc, the locations of the relief camps are selected depending upon the human resources in such a manner that all the effected peoples can get different services with the minimum effort and expenditure. Mobile communication tower points are selected in such a way that covers all the customers' area with the minimum expenditure. So, the CSP has a wide range of applications in the real life problems.

As CSP belongs to the class of NP-hard problems, exact (analytical approach) algorithms are not suitable to find the solution of a CSP in a usable time window. So heuristic approaches are applicable to find a compromise solution in a specific time window. The initial study in this direction was made by current and schilling[1] in 1989. They proposed the problem and the problem was solved by the authors using a two phase heuristics approach. In the first phase of the algorithm, the set covering approach is followed to find the clusters of the vertex set. Then one node from each cluster is selected as the facility node. Then a traveling salesman problem (TSP) is formed through the selected nodes. In the second phase, this TSP is solved using any suitable heuristics approach. These two phases are repeated iteratively to search the best path.

Using Lin-Kernighan procedure [16], Golden et al. [7] proposed two heuristics search algorithms, $L S_{1}$ and $L S_{2}$ for solving different CSPs in 2012. Both the algorithms start with a randomly generated set of feasible solutions of the problem. Then $L S_{1}$ uses some stochastic approach to replace some nodes from the path by some new nodes to improve the quality of the solution in such a manner that the feasibility of the solution persists. The authors used mutation operations to prevent any local optima and used some uphill moves to introduce diversity in the algorithm. On the other hand $L S_{2}$ uses two iterative procedures, namely, the Improvement Procedure and the Perturbation Procedure to find the best feasible solution.

Using the features of integer linear programming (ILP) Salari and Naji-Azimi[24] proposed a Heuristics method for solving CSP in 2012. The algorithm starts with a randomly generated set of feasible solutions of the problem and the tour is improved iteratively using two procedures, namely, Heuristic based improvement and ILP based improvement. An ExtractionReassignment procedure is used to decrease the tour length in the heuristic phase. At first, a subset of the vertices visited by the tour is extracted and then this vertices are reassigned into a new tour by solving the ILP model for the improvement of the objective function. Another heuristic algorithm by Lin-Kernighan[16] is also used for the possible improvement of the tour. Also, a perturbation phase is introduced in the algorithm to escape from the local optima.

Similar to the CSP, another problem, named, Covering Tour Problem (CTP), was proposed by Gendreau et al.[6] in 1992. In this problem the set of vertices, $V$, is partitioned into to two subsets $V_{1}$ and $V_{2}$ and the goal is to search a minimum cost Hamiltonian circuit through $V_{1}$ so that the distance of each of the vertices of $V_{2}$ from the circuit is located within a prescribed distance. They first formulate the problem as an ILP problem and then an exact branch and cut algorithm is developed to solve the problem. They have also proposed a heuristics approach for it. In a recent study, Singh et al. [22] proposed a mixed integer programming model for a bi-objective generalised covering salesman problem, where simultaneously, the total covered demand is maximised and the total tour length is minimised.

Combining the features of ant colony optimization (ACO) algorithm and the dynamic programming technique, Salari et al[25] proposed a heuristic approach to solve CSPs. Together with 3-opt, they introduced two perturbation approaches vertex-removal and vertex-addition for searching quality solutions. Venkatesh and Singh [29] modified the Artificial Bee Colony (ABC) algorithm with different perturbation techniques to solve the CSPs in 2019. Venkatesh 
et al.[29] proposed a local search heuristic for the CSPs using multiple perturbation strategy. In another study, Pandiri et al.[22] modified two heuristic approaches ABC and Genetic Alorithm (GA) to solve CSPs in 2020. They proposed four approaches for selecting neighbour solutions in both the algorithms- GA and ABC, namely, Subset Neighbour, Local search with two neighbour structures, General Exchange and Permutation neighbour. Zang et al.[31] defined Bilevel CSP(BCSP) and proposed two algorithms based on, parallel variable neighbourhood search (PVNS), namely, synchronous master slave PVNS and asynchronous cooperative PVNS, for the same. A crossover procedure using GPX was proposed by Tripathy et al. [27] and using it a GA was developed by them for the CSPs in 2017.

Though a significant amount of studies is made on the CSPs after its introduction by current and schilling[1] there are some lacunas in the existing literature, which are summarised below:

- The well-established algorithm for any routing problem is the ACO, but not much attention has been paid to solve the CSPs using ACO [25].

- It is known that, a CSP involves two phases- division of cities into groups with the selection of visiting cities and searching of the minimum cost Hamiltonian circuit through the visiting cities. But, none of the studies in the literature is made following this direct approach.

- Moreover, none of the studies gives attention to reduce the total travel distance of the unvisited cities from the visited city of a group. Though in real life problem it is crucial as different facilities are provided from the visited cities only.

- Also, there is no algorithm in the literature, which gives results of the CSP instances with the specified coverage range $r$. All the studies have been made where groups are created with the nearest nodes from the selected centres of the groups.

- All the studies upto till date proposed different heuristics for CSPs for the betterment of the existing results, which in turn motivates us for the further betterment.

- In all the above studies, it is observed that the problems are considered in the crisp environment only, i.e., the cost of travel between any two specific cities is fixed, which is unrealistic in any real life situation. In fact, the cost of travel between any two places varies with several factors, like, road conditions, type of vehicle used, the route used, etc. This cost is actually imprecise in nature and can be estimated as rough or fuzzy number using experts' opinion. This type of estimation is less error prone as it is done using experts' opinion. Though there are algorithms to solve basic TSPs and its variants in the imprecise environments[11, 12, 13], none has introduced any algorithm to solve the CSPs in any imprecise environment.

- Though algorithms are available to solve TSPs in the imprecise environments $[12,13]$, the approach cannot deal with the problems involving fuzzy data with non-linear membership functions (e.g., Parabolic Fuzzy Number(PFN)) or TSPs involving Rough data where the estimation can not be done using Lebesgue measure.

To overcome the above mentioned lacunas, in this study an attempt has been made to introduce a better heuristic approach to solve the CSPs in the crisp and as well as in the imprecise environments. Simulation approaches in the imprecise environments are proposed to deal with the CSPs in the imprecise environments for any type of imprecise data sets. Moreover, a restricted problem is introduced and solved where the total travel distance of different unvisited cities from the visited city of the corresponding group should not exceed a prescribed limit. 
The heuristic algorithm proposed here consists of three phases. In the first phase of the algorithm, the set of cities is partitioned into groups depending upon the maximum number of cities in a group and the total number of groups. A procedure is proposed for this purpose where initially a centre of each group is selected and then other cities of the group are selected in such a manner that all other cities are located within the specified coverage range $r$. The centre of the next group is selected from the unselected cities which is nearest to this center. In the second phase of the algorithm, the ACO [4] is used to find the shortest/minimum-cost path of the problem by visiting only the centre of each group. In the last phase, the K-opt algorithm is used to improve the quality of the solution obtained by the ACO and to resist premature convergence. For the restricted problem, the path is searched in such a manner that the total distance/cost of different unvisited cities of a group from the visited city of the corresponding group should not exceed a predefined upper limit. To solve the problem in an imprecise environment an approach is followed, where, the tour is searched without transferring the imprecise optimisation problem into any equivalent crisp optimisation problem. Moreover, fuzzy simulation and rough simulation approaches are proposed to deal with the problem with any general type imprecise data set.

The rest of the paper is organized as follows: in section 2, the background and the main challenges of solving the CSPs in different environments are discussed. The required assumptions and different notations for the mathematical representation of the problem and the development of the proposed algorithm are listed in section 3. The mathematical representation of the problem and some technical prerequisites for the proposed solution approach are presented in section 4. Optimization in imprecise environments and the simulation approaches are discussed in section 5. The ACO algorithm for the CSP is described in section 6. In section 7, the K-Opt algorithm is presented. Proposed approach is presented in section 8. Experimental results are discussed in section 9. A brief conclusion is drawn in section 10. At length, the references are listed.

\section{BACKGROUND OF THE CSP AND CHALlENGES}

CSP was defined by Current and Schilling[1] in 1989. They formulated the problem as a zeroone linear programming problem (LPP) and proposed a heuristic approach to solve the same. In their approach, in the first step, the subset of cities to cover all the cities are determined using the approach of solving a set covering problem (SCP). For each of the solution of SCP, a TSP is generated and solved. The minimum cost tour is the solution of the CSP. As SCP and TSP, both are NP-hard problems, so, it is not possible to solve a moderate size CSP in a reasonable time window following this approach.

Combining the features of dynamic programming technique, ACO and amalgamating different perturbation techniques, like, 3-opt, vertex removal and vertex addition techniques, etc., Salari et al.[25] developed a novel heuristic to solve CSPs in 2015. In this study paths are created by selecting successive cities using ACO until all the cities are covered. Then, the vertex removal and vertex addition techniques are used to improve the tour cost. Finally, 3-opt operation is applied on the path for further possible improvements. This study ignores the restriction of the upper limit, $r$, of the coverage range of the unvisited cities and consider only the nearer nodes of any visiting city as the covered nodes for searching the path.

In a recent study, Pandiri et al. [22] proposed two meta-heuristics for the CSPs. In the first approach, ABC algorithm is modified for the CSPs using four perturbation operations on a tour. One of these approach is the removal of a visited vertex and addition of an unvisited 
vertex which can cover the removed vertex and they named it LS2N. Another approach is the permutation of neighbour, where, some permutation is made on the positions of the visited cities in a tour to improve the quality. The third approach is the general exchange (GE) of an unvisited city with a visited city, such that the feasibility of the tour holds. The fourth approach is named subset neighbour (SSBN) and in this approach some cities of a tour are removed with some probability and some unvisited cities are added so the tour becomes feasible as well as the quality is improved. Using these perturbation approaches they, developed a tour improvement algorithm and is used in the employed bee phase and in the onlooker bee phase of the basic ABC to make it useful for the CSPs. For the generation of initial solution set for the ABC as well as for the GA approach they followed the same approach as Salari et al.[25]. In GA cyclic crossover operation is used and for the mutation process they proposed two new approaches. They have also used the perturbation approaches of the $\mathrm{ABC}$ algorithm in the GA for the further possible improvements. Performances of both these approaches are similar to the hybrid ACO proposed by Salari et al.[25]. So the approaches of Pandiri et al. [22] did not give better solution than that of Salari et al.[25]. Moreover, this study also ignores the restriction of the upper limit, $r$, of the coverage range of the unvisited cities and consider only the nearer nodes of any visiting city as the covered nodes for searching the path.

All the above studies as well the studies mentioned in the introduction section, the initial paths are created using successive addition of visiting cities to cover all the cities following the approaches of set covering problem, but none has mentioned the covering range in their test instances, i.e., the maximum distance of an unvisited city from its nearest visiting city, though the tour cost mostly depends on it and it is also the basic restriction of the problem. Also, none of these studies tries to reduce the total group covering distance of a visiting city, though it is realistic one for any real life problem. Since, the CSP is a routing problem, selection of the visiting cities and the determination of the optimal rout through these cities using any suitable routing algorithm, may produce better result (as proposed by Current and Schilling[1]). But the approach is overlooked by the researchers for developing any heuristic approach. Moreover, none have studied the CSPs in imprecise environments. There are some studies on the TSPs and GTSPs with fuzzy cost matrices and rough cost matrices [11, 12, 13], using the credibility measure on fuzzy events and the trust measure on rough events, where TFNs are used as the fuzzy parameters and the Lebesgue measure is used for the estimation of rough parameters. Their approach can not deal with such problems involving fuzzy cost matrices with non-linear membership functions. In fact, when more than one fuzzy parameters with non-linear membership function (e.g., PFN) are added then it is not possible to determine the analytical form of the membership function of the resultant fuzzy number. So following their approach it is not possible to determine the credibility measure of the fuzzy events involving the process when the membership functions of the fuzzy parameters are non-linear type. The same problem has to be face in the rough environment also, if the Lebesgue measure is not possible to use for the rough estimation.

To overcome these limitations in this study fuzzy simulation approach and rough simulation approaches are proposed to deal with such crucial situations. Moreover, the CSP is solved with an approach where initially the cities are divided into groups selecting one possible visiting city of each group. Then the routing heuristic ACO is used to determine the optimal route through the visiting cities. K-opt operation is also used periodically for the possible improvement of the best path found so far and to resist any premature convergence. In a particular case, the CSP is solved with the restriction limit of the total group coverage range as well as incorporating the normal restriction on the coverage range, $r$. 


\section{Assumptions and Notations}

Following assumptions and notations are used to formulate the problem:

(i) $n$ is the number of cities involved in the problem.

(ii) $N C$ is the maximum number of unvisited cities covered by a visiting city.

(iii) $N B$ is the maximum number of cluster of cities.

(iv) $c_{i j}$ is the travelling distance/cost between city $i$ and city $j$.

(v) $r$ is the maximum distance between a visiting city and the furthest unvisited city covered by that visiting city.

(vi) $\left(x_{i j}\right)_{n \times n}$ is the decision variable matrix for the mathematical representation of the problem

where $x_{i j}= \begin{cases}1 & \text { if the salesman moves to city } j \text { from city } i \\ 0 & \text { otherwise }\end{cases}$

(vii) Another array variable $\left(v_{i}\right)_{1 \times n}$, is also used for the mathematical representation of the problem, where,

$v_{i}= \begin{cases}1 & \text { if the salesman visits city } i \\ 0 & \text { otherwise }\end{cases}$

(viii) Also the coverage matrix $\left(y_{i j}\right)_{n \times n}$ is defined as

$$
y_{i j}= \begin{cases}1 & \text { if } c_{i j} \leq r \\ 0 & \text { otherwise }\end{cases}
$$

(ix) $Z$ is the total tour cost/travel distance.

(x) The ascent $\sim$ is used over a symbol to indicate fuzzy quantity.

(xi) The ascent ${ }^{\sim}$ is used over a symbol to indicate rough quantity.

\section{Technical Background}

Covering Salesman Problem: The basic CSP consists of a set of cities $V=\{1,2, \ldots n\}$ where the travelling distance/ cost between any two cities $i$ and $j$ is known and fixed, say $c_{i j}$. The goal of the problem is to search a minimum distance Hamiltonian circuit through a subset of cities so that the position of every unvisited city is located within a predefined coverage range $r$ of a visited city. Then the problem mathematically takes the following form

$$
\begin{aligned}
\text { Minimize } & Z=\sum_{i \in V} \sum_{j \in V} c_{i j} x_{i j} \\
\text { Subject to } \quad & \sum_{j \in V} x_{i j}+\sum_{j \in V} x_{j i}=2 v_{i} \forall i \in V \\
& \sum_{j \in V} y_{j i} v_{j} \geq 1 \forall i \in V \\
\sum_{i \in S} \sum_{j \in V \backslash S} x_{i j}+ & \sum_{i \in V \backslash S} \sum_{j \in S} x_{i j} \geq 2\left(v_{l}+v_{k}-1\right), S \subset V, 2 \leq|S| \leq n-2, \forall l \in V, k \in V \backslash S
\end{aligned}
$$

In the formulation, the objective function $Z$ is the total travel distance of the tour, which is to be minimized. Constraints set (5) implies that if the salesman visits a city he must left the city after his visit. Constraints set (6) implies that every vertex in the vertex set $V$ is located in a covering distance $r$ from a visited city. Finally, equation set (7) implies that the tour should not contain any sub-tour.

In the existing literature, every problem consists of a predefined number of clusters $(N B)$ and upper limit $(N C)$ of the number of cities in a cluster. A salesman should visit only one city of each cluster so that the problem constraints are satisfied. 
To solve the problem here following steps are followed:

- At first randomly select a city $c_{1}$ to be visited, and search $N C-1$ cities nearest to the selected city. If these cities are located inside the covering distance $r$, then this set of vertices is named as the first cluster. If it is not true then another vertex is selected and the same process is continued until a cluster is created.

- After the formation of a cluster, the nodes in the clusters are eliminated from the node set and let it be $V_{1}$.

- Select next city $c_{2}$ to be visited from $V_{1}$ which is nearest to $c_{1}$ and form a cluster following the same procedure as first cluster. If fails then the next nearest node of $V_{1}$ from $c_{1}$ is selected as $c_{2}$ and the process is continued.

- Following the same procedure, different clusters are created. In this formation, in any step if it fails to create a cluster then the process again starts from the formation of first cluster.

A salesman at first partitioned the cities into some clusters according to the constraints. Then the salesman visits one of the cities of each group which is located within the coverage range $r$ of all the unvisited cities for the selling/canvassing/distribution of some products to its customers of the different cities of the groups. The goal of the problem is threefold:

- First partition the cities into clusters depending upon the maximum number of cities in a cluster and clusters limit.

- Search a minimum cost path for the traveller through all the clusters by visiting only one city of each cluster.

- Every unvisited city must lies within a predefined covering distance from a visited city.

Fuzzy Number: A fuzzy set $\tilde{F}$ is defined on an universe $U$ such that every $u \in U$ belongs to the set $\tilde{F}$ with some degree of membership $\mu_{F}(u) \in[0,1]$. The function $\mu_{F}: U \rightarrow[0,1] \subset \mathbb{R}$ is called the membership function of the fuzzy set $\tilde{F}$. In other words the function $\mu_{F}$ completely defines the fuzzy set $\tilde{F}$ on $U$. A fuzzy set normally denoted by using an ascent ${ }^{\sim}$ over the name. A fuzzy number $\tilde{A}$ is a fuzzy set on $\mathbb{R}$ such that its membership function $\mu_{A}$ satisfies the following two conditions [30]:

- $\exists a \in \mathbb{R}$ such that $\mu_{A}(a)=1$.

- $\forall a, b \in \mathbb{R}$ and $\lambda \in(0,1), \mu_{A}(\lambda a+(1-\lambda) b) \geq \min \left\{\mu_{A}(a), \mu_{A}(b)\right\}$

Triangular Fuzzy Number (TFN): A TFN $\tilde{A}$ having membership function $\mu_{A}$ has positive membership in an interval [a,c] and has membership value 1 at only one point $b \in[a, c]$. It is denoted by $\tilde{A}=(a, b, c)$ and its membership function $\mu_{\tilde{A}}$ is given by

$$
\mu_{\tilde{A}}(x)=\left\{\begin{array}{ccc}
\frac{x-a}{b-a} & \text { for } & a \leq x \leq b \\
\frac{c-x}{c-b} & \text { for } & b \leq x \leq c \\
0 & & \text { otherwise }
\end{array}\right.
$$

Parabolic fuzzy number (PFN).: A PFN $\tilde{A}$ having membership function $\mu_{A}$ has positive membership in an interval $[\mathrm{a}, \mathrm{c}]$ and has membership value 1 at only one point $b \in[a, c]$. It is 
denoted by $\tilde{A}=(a, b, c)$ and its membership function $\mu_{\tilde{A}}$ is given by

$$
\mu_{\tilde{A}}(a)=\left\{\begin{array}{ccc}
1-\frac{(b-x)^{2}}{(b-a)^{2}} & \text { for } & a \leq x \leq b \\
1-\frac{(x-b)^{2}}{(c-b)^{2}} & \text { for } & b \leq x \leq c \\
0 & & \text { otherwise }
\end{array}\right.
$$

Fuzzy extension principle: Let $f:\left(X_{1} \times X_{2} \times \ldots \times X_{n}\right) \rightarrow Y$ be a function and $\tilde{A}_{1}, \tilde{A}_{2}, \ldots$, $\tilde{A}_{n}$ are fuzzy sets defined on $X_{1}, X_{2}, \ldots, X_{n}$, respectively. Then $\tilde{B}=f\left(\tilde{A}_{1} \times \tilde{A}_{2} \times \ldots \times \tilde{A}_{n}\right)$ is a fuzzy set defined on $Y$ whose membership function is defined by the extension principle and the set is given by:

$$
\tilde{B}=\left\{\left(y, \mu_{B}(y)\right) \mid \mu_{B}(y)=\max _{x_{1} \in X_{1}, x_{2} \in X_{2}, \ldots, x_{n} \in X_{n}}\left\{\min \left(\mu_{A_{1}}\left(x_{1}\right), \mu_{A_{2}}\left(x_{2}\right), \ldots, \mu_{A_{n}}\left(x_{n}\right)\right), y=f\left(x_{1}, x_{2}, \ldots, x_{n}\right)\right\}\right\}
$$

$\alpha$-cut of a fuzzy number: Let $\tilde{F}$ be a fuzzy number with membership function $\mu_{F}$. Then $\alpha$-cut of $\tilde{F}$ is a subset of $\mathbb{R}$ denoted by $\tilde{F}_{\alpha}$ and defined as

$$
\tilde{F}_{\alpha}=\left\{x \in \mathbb{R}: \mu_{F}(x) \geq \alpha\right\}
$$

Credibility Measure(Cr): If $\tilde{A}$ and $\tilde{B}$ be two fuzzy numbers. Then $\tilde{A} \star \tilde{B}$ is a fuzzy event, where $* \in\{<,>, \leq, \geq,=\}$. Considering the level of uncertainty as the semantics of fuzzy numbers, credibility measure of the event $\tilde{A} \star \tilde{B}$ is denoted by $\operatorname{Cr}(\tilde{A} \star \tilde{B})$ and is defined as

$$
\begin{aligned}
\operatorname{Cr}(\tilde{A} \star \tilde{B}) & =\frac{1}{2}[\operatorname{Pos}(\tilde{A} \star \tilde{B})+\operatorname{Nes}(\tilde{A} \star \tilde{B})] \\
\text { where } \operatorname{Pos}(\tilde{A} \star \tilde{B}) & =\sup \left\{\min \left(\mu_{\tilde{A}}(a), \mu_{\tilde{B}}(b)\right): a, b \in \mathbb{R}, \text { such that } a * b \text { holds }\right\} \\
\text { and } \operatorname{Nes}(\tilde{A} \star \tilde{B}) & =1-\operatorname{Pos}(\tilde{A} \star \tilde{B}), \text { where } \tilde{\tilde{A} \star \tilde{B}} \text { denotes the complement of } \tilde{A} \star \tilde{B}(1
\end{aligned}
$$

Lemma 1[10]: For any two TFNs $\tilde{A}=\left(A_{1}, A_{2}, A_{3}\right)$ and $\tilde{B}=\left(B_{1}, B_{2}, B_{3}\right)$

$$
\begin{gathered}
\operatorname{Pos}(\tilde{A}>\tilde{B})=\left\{\begin{array}{cl}
0 & A_{3} \leq B_{1} \\
\frac{A_{3}-B_{1}}{B_{2}-B_{1}+A_{3}-A_{2}} & A_{3} \geq B_{1} \text { and } A_{2} \leq B_{2} \\
1 & A_{2} \geq B_{2}
\end{array}\right. \\
\text { and } N e s(\tilde{A}>\tilde{B})=\left\{\begin{array}{cl}
0 & A_{2} \geq B_{2} \\
\frac{A_{2}-B_{2}}{B_{3}-B_{2}+A_{2}-A_{1}} & B_{2} \leq A_{2} \\
1 & A_{1} \geq B_{3}
\end{array} \text { and } A_{1} \leq B_{3}\right.
\end{gathered}
$$

Lemma 2[10]: For any two PFNs $\tilde{A}=\left(A_{1}, A_{2}, A_{3}\right)$ and $\tilde{B}=\left(B_{1}, B_{2}, B_{3}\right)$

$$
\begin{gathered}
\operatorname{Pos}(\tilde{A}>\tilde{B})=\left\{\begin{array}{cl}
0 & A_{3} \leq B_{1} \\
1-\left(\frac{B_{2}-A_{2}}{A_{3}-A_{2}+B_{2}-B_{1}}\right)^{2} & A_{3} \geq B_{1} \text { and } A_{2} \leq B_{2} \\
1 & B_{2} \leq A_{2}
\end{array}\right. \\
\text { and } N e s(\tilde{A}>\tilde{B})=\left\{\begin{array}{cl}
0 & B_{2} \geq A_{2} \\
1-\left(\frac{A_{2}-B_{2}}{B_{3}-B_{2}+A_{2}-A_{1}}\right)^{2} & B_{2} \leq A_{2} \\
1 & A_{1} \geq B_{3}
\end{array} \text { and } A_{1} \leq B_{3}\right.
\end{gathered}
$$


Lemma 3:If for any fuzzy event $\tilde{A} * \tilde{B}, \operatorname{Nes}(\tilde{A} * \tilde{B})>0$ then $\operatorname{Cr}(\tilde{A} * \tilde{B})>0.5$.

$$
\begin{array}{cl}
\text { Proof } & \operatorname{Nes}(\tilde{A} * \tilde{B})>0 \Rightarrow 1-\operatorname{Pos}(\tilde{\tilde{A} * \tilde{B}})>0 \Rightarrow \operatorname{Pos}(\tilde{\tilde{A}} * \tilde{B})<1 \Rightarrow \operatorname{Pos}(\tilde{A} * \tilde{B})=1 \\
\Rightarrow \quad \operatorname{Cr}(\tilde{A} \star \tilde{B})=\frac{1}{2}[\operatorname{Pos}(\tilde{A} \star \tilde{B})+\operatorname{Nes}(\tilde{A} \star \tilde{B})] \Rightarrow \operatorname{Cr}(\tilde{A} * \tilde{B})>0.5
\end{array}
$$

Lemma 4[20]: For any fuzzy event $\tilde{A} * \tilde{B}, \operatorname{Cr}(\tilde{A} * \tilde{B})+\operatorname{Cr}(\overline{\tilde{A} * \tilde{B})}=1$.

Lemma 5[10]: For any two TFNs $\tilde{A}=\left(A_{1}, A_{2}, A_{3}\right)$ and $\tilde{B}=\left(B_{1}, B_{2}, B_{3}\right)$

$$
C r(\tilde{A}<\tilde{B})=\left\{\begin{array}{cl}
0 & A_{3} \leq B_{1} \\
\frac{1}{2}\left(1+\frac{B_{2}-A_{2}}{A_{3}-A_{2}+B_{2}-B_{1}}\right) & A_{2} \leq B_{2} \text { and } B_{1}<A_{3} \\
\frac{1}{2}\left(\frac{B_{3}-A_{1}}{B_{3}-B_{2}+A_{2}-A_{1}}\right) & B 2<A 2 \text { and } B_{3}>A_{1} \\
0 & \mathrm{~B}_{3}<A_{1}
\end{array}\right.
$$

Rough variable[19]: A rough variable $\hat{y}$ is a quantifiable function within the rough space $(\Lambda, \Delta, \kappa, \pi)$ to the set of real numbers $\mathbb{R}$. That is for every Borel set $B$ of $\mathbb{R}$, we have $\{\lambda \in$ $\Lambda \mid \hat{y}(\lambda) \in B\} \in \kappa$. The lower and upper approximations of the rough variable, $\hat{y}$, are defined as $\underline{\hat{y}}=\{\hat{y}(\lambda) \mid \lambda \in \Delta\}$ and $\overline{\hat{y}}=\{\hat{y}(\lambda) \mid \lambda \in \Lambda\}$ respectively.

Trust measure[19]: Let $(\Lambda, \Delta, \kappa, \pi)$ be a rough space. Then the trust measure of a rough event $R$ is denoted by $\operatorname{Tr}(R)$ and is defined as

$$
\operatorname{Tr}(R)=\frac{1}{2}[\underline{\operatorname{Tr}}(R)+\overline{\operatorname{Tr}}(R)]
$$

where $\underline{\operatorname{Tr}}(R)=\frac{\pi(R \cap \Delta)}{\pi(\Delta)}$ and $\overline{\operatorname{Tr}}(R)=\frac{\pi(R)}{\pi(\Lambda)}$ are the lower and upper trust measure of the rough event $R$ respectively. A rough set normally denoted by using an ascent`over the name.

Lemma 6[23]: Let Lebesgue measure is used for trust measure and $\hat{R}_{1}=\left(\left[p_{1}, q_{1}\right]\left[r_{1}, s_{1}\right]\right)$, $\hat{R}_{2}=\left(\left[p_{2}, q_{2}\right]\left[r_{2}, s_{2}\right]\right)$ be two rough variables. Then trust measure of the rough event $\hat{R}_{1}<\hat{R}_{2}$ is denoted by $\operatorname{Tr}\left(\hat{R}_{1}<\hat{R}_{2}\right)$ and is given by

$$
\operatorname{Tr}\left(\hat{R}_{1}<\hat{R}_{2}\right)= \begin{cases}0 & \text { for } s_{2}-r_{1} \leq 0 \\ \frac{s_{2}-r_{1}}{2\left(s_{2}-r_{1}-r_{2}+s_{1}\right)} & \text { for } q_{2}-p_{1} \leq 0 \leq s_{2}-r_{1} \\ \frac{1}{2}\left(\frac{s_{2}-r_{1}}{s_{2}-r_{1}-r_{2}+s_{1}}+\frac{q_{2}-p_{1}}{q_{2}-p_{1}-p_{2}+q_{1}}\right) & \text { for } p_{2}-q_{1} \leq 0 \leq q_{2}-p_{1} \\ \frac{1}{2}\left(\frac{s_{2}-r_{1}}{s_{2}-r_{1}-r_{2}+s_{1}}+1\right) & \text { for } r_{2}-s_{1} \leq 0 \leq p_{2}-q_{1} \\ 1 & \text { for } r_{2}-s_{1} \geq 0\end{cases}
$$

Lemma 7[20]: For any rough event $\hat{A} * \hat{B}, * \in\{<, \leq,>, \geq\}, \operatorname{Tr}(\hat{A} * \hat{B})+\operatorname{Tr}(\overline{\hat{A} * \hat{B})}=1$.

CSP in imprecise environment: In the problem (4) when some of the cost parameters are imprecise(Fuzzy/Rough etc.) in nature then the goal of the problem reduces to the determination of optimal path under minimization of imprecise objective. So the problem reduces to optimization in the imprecise environment(Fuzzy/Rough etc.)

\section{OptimizATION IN IMPRECISE ENVIRONMENT}

Let us consider an optimization problem in the form:

$$
\left.\begin{array}{cl}
\text { Maximize } & f(x, y) \\
\text { subject to } & \phi_{i}(x, y) \leq 0, i=1,2, \ldots p
\end{array}\right\}
$$

Here $x=\left(x_{1}, x_{2}, \ldots, x_{n}\right)$ is a decision vector having $n$ variables, $y=\left(y_{1}, y_{2}, \ldots, y_{m}\right)$ is a vector representing, $m$, parameters of the problem and $\phi_{i}(x, y), i=1,2, \ldots p$ are constraint functions. 
In any classical optimization problem, the parametric values are crisp in nature. When the parameters are imprecise in nature, the problem (18) reduces to optimization in imprecise environment.

5.1. Optimization in fuzzy environment. In the problem (18), if $y$ is a vector of fuzzy numbers, $\tilde{y}=\left(\tilde{y}_{1}, \tilde{y}_{2}, \ldots, \tilde{y}_{m}\right)$, the problem (18) reduces to an optimization problem in fuzzy environment having $n$ crisp decision variables, $x_{1}, x_{2}, \ldots, x_{n}$, and is presented below:

$$
\left.\begin{array}{ll}
\text { Maximize } & \tilde{f}(x, \tilde{y}) \\
\text { Subject to } & \tilde{\phi}_{i}(x, \tilde{y}) \leq 0, i=1,2, \ldots p
\end{array}\right\}
$$

clearly here objective function as well as the constraints are fuzzy in nature. Optimization in fuzzy environment is not properly defined till date. Moreover, there is no proper guideline to check whether the value of a decision vector is feasible with respect to the constraints involve in the problem. In problem(19) the value $x_{0}$ of the decision vector $x$ may said to be feasible if the following condition holds

$$
\operatorname{Cr}\left(\tilde{\phi}_{i}(x, \tilde{y}) \leq 0\right)>0.5, \forall i \in\{1,2, \ldots p\}
$$

It is a valid approach as $\operatorname{Cr}\left(\tilde{\phi}_{i}(x, \tilde{y}) \leq 0\right)+\operatorname{Cr}\left(\tilde{\phi}_{i}(x, \tilde{y})>0\right)=1(\S$ Lemma 4). Similarly, a feasible solution $x^{\prime}$ is better than another feasible solution $x^{\prime \prime}$ if

$$
\operatorname{Cr}\left(\tilde{f}\left(x^{\prime}, \tilde{y}\right)>\tilde{f}\left(x^{\prime \prime}, \tilde{y}\right)\right)>0.5
$$

If the analytical form of the membership functions of the constraint functions $\tilde{\phi}_{i}(x, \tilde{y}), i=$ $1,2, \ldots, p$ are available then similar as, Lemma 5 , one can easily determine the values of $\operatorname{Cr}\left(\tilde{\phi}_{i}(x, \tilde{y}) \leq 0\right), i=1,2, \ldots, p$ for the determination of the feasibility of any value of the decision vector, $x$. Similarly if the analytical form of the membership function of the fuzzy objective $\tilde{f}(x, \tilde{y})$ is available then one can easily determine the values of $\operatorname{Cr}\left(\tilde{f}\left(x^{\prime}, \tilde{y}\right)>\tilde{f}\left(x^{\prime \prime}, \tilde{y}\right)\right)$ for the determination of the better option between two feasible values, $x^{\prime}$ and $x^{\prime \prime}$ of the decision vector, $x$. But if the analytical form of the membership function of any constraint or the analytical form of the membership function the objective function is not available then fuzzy simulation approach can be used for the validation of any constraint in (20) or (21). It can be done using the following algorithm.

Algorithm 1. Algorithm to verify $\operatorname{Cr}\left(\tilde{\phi}_{i}(x, \tilde{y}) \leq 0\right)>0.5$ for a particular value of the decision vector $x$.

From Lemma-3, it can be stated that, for a decision vector $x$ if $N e s\left(\tilde{\phi}_{i}(x, \tilde{y}) \leq 0\right)>0$ then $\operatorname{Cr}\left(\tilde{\phi}_{i}(x, \tilde{y}) \leq 0\right)>0.5$. Also $N e s\left(\tilde{\phi}_{i}(x, \tilde{y}) \leq 0\right)>\alpha \Rightarrow \operatorname{Pos}\left(\tilde{\phi}_{i}(x, \tilde{y}) \geq 0\right)<1-\alpha$. So $\operatorname{Cr}\left(\tilde{\phi}_{i}(x, \tilde{y}) \leq 0\right)>0.5 \Leftrightarrow \operatorname{Pos}\left(\tilde{\phi}_{i}(x, \tilde{y}) \geq 0\right)<1-\alpha$ for any $\alpha>0$. The following algorithm, checks the feasibility of the statement $\operatorname{Pos}\left(\tilde{\phi}_{i}(x, \tilde{y}) \geq 0\right)<1-\alpha$, i.e., feasibility of the statement $\operatorname{Cr}\left(\tilde{\phi}_{i}(x, \tilde{y}) \leq 0\right)>0.5$.

1. Input $x$

2. Initialize $N$

3. $j \leftarrow 1$

4. Select randomly one vector $y_{0}$ from $[\tilde{y}]_{1-\alpha}$

5. If $\phi_{i}\left(x, y_{0}\right) \geq 0$

6. Return Infeasible

7. End If

8. $j \leftarrow j+1$

9. If $j \leq N$

10. Go to step 4 .

11. End If 
12. Return Feasible

13. End Algorithm

5.2. Optimization in rough environment. In the problem (18), if $y$ is a vector of rough numbers, $\hat{y}=\left(\hat{y}_{1}, \hat{y}_{2}, \ldots, \hat{y}_{m}\right)$, the problem (18) reduces to an optimization problem in rough environment having $n$ crisp decision variables, $x_{1}, x_{2}, \ldots, x_{n}$, and is presented below:

$$
\left.\begin{array}{ll}
\text { Maximize } & \hat{f}(x, \hat{y}) \\
\text { Subject to } & \hat{\phi}_{i}(x, \hat{y}) \leq 0, i=1,2, \ldots p
\end{array}\right\}
$$

clearly here objective function as well as the constraints are rough in nature. Optimization in rough environment is not properly defined till date. Moreover, there is no proper guideline to check whether the value of a decision vector is feasible with respect to the rough constraints involve in the problem. In problem $(22)$ the value $x_{0}$ of the decision vector $x$ may said to be feasible if the following conditions hold

$$
\operatorname{Tr}\left(\hat{\phi}_{i}\left(x_{0}, \hat{y}\right) \leq 0\right)>0.5, \forall i \in\{1,2, \ldots p\}
$$

It is a valid approach as $\operatorname{Tr}\left(\hat{\phi}_{i}\left(x_{0}, \hat{y}\right) \leq 0\right)+\operatorname{Tr}\left(\tilde{\phi}_{i}\left(x_{0}, \tilde{y}\right)>0\right)=1(\S$ Lemma 7$)$. Similarly, a feasible solution $x^{\prime}$ is better than another feasible solution $x^{\prime \prime}$ if

$$
\operatorname{Tr}\left(\hat{f}\left(x^{\prime}, \hat{y}\right)>\hat{f}\left(x^{\prime \prime}, \hat{y}\right)\right)>0.5
$$

If the analytical form of the constraint functions $\hat{\phi}_{i}(x, \tilde{y}), i=1,2, \ldots, p$ are available then similar as, Lemma 6 , one can easily determine the values of $\operatorname{Tr}\left(\hat{\phi}_{i}(x, \hat{y}) \leq 0\right), i=1,2, \ldots, p$ for the determination of the feasibility of any value of the decision vector, $x$. Similarly if the analytical form of the rough objective $\hat{f}(x, \hat{y})$ is available then one can easily determine the values of $\operatorname{Tr}\left(\hat{f}\left(x^{\prime}, \hat{y}\right)>\hat{f}\left(x^{\prime \prime}, \tilde{y}\right)\right)$ for the determination of the better option between two feasible values, $x^{\prime}$ and $x^{\prime \prime}$ of the decision vector, $x$. But if the analytical form of any constraint or the analytical form of the objective function is not available then rough simulation approach can be used for the validation of any constraint in (23) or (24). It can be done using the following algorithm.

Algorithm 2. Algorithm for the determination of $\operatorname{Tr}\left(\hat{\phi}_{i}(x, \hat{y}) \leq 0\right)$ for a particular value of the decision vector $x$.

Let $\hat{y}$ be an $m$ dimensional rough vector on the rough space $(\Lambda, \Delta, \kappa, \pi)$ then $\hat{\phi}(x, \hat{y})$ is also a rough vector on that space. To find the trust measure of the rough event $\hat{\phi}(x, \hat{y}) \leq 0$, the following algorithm can be used:

1. Let $n_{1}=n_{2}=0$ and set value of $N$, sufficiently large.

2. Generate $\underline{\lambda}$ uniformly from $\Delta$ according to the measure $\pi$

3. If $\phi(x, y(\underline{\underline{\lambda}})) \leq 0$ then $n_{1}=n_{1}+1$.

4. Generate $\bar{\lambda}$ uniformly from $\kappa$ according to the measure $\pi$

5. If $\phi(x, y(\bar{\lambda})) \leq 0$ then $n_{2}=n_{2}+1$.

6. Repeat the steps $2-5$ for $N$ times.

7. $\operatorname{Tr}(\hat{\phi}(x, \hat{y}) \leq 0)=\left(n_{1}+n_{2}\right) /(2 N)$

8. End algorithm

\section{Ant Colony Optimization}

Following different behaviours of ants for searching their food sources, the ACO algorithm was proposed by Dorigo et al.[4] in 1997 to solve TSPs. In the algorithm, the path of an ant from the nest to the food source is analogous to the path of a salesman in TSP. Ant algorithm are multi-agent system in which the behaviour for each single agent, called artificial ant or ant, follows real ants's behaviour. Nowadays, a large no of algorithms on ant base has been available in the literature. The purpose of the algorithm is to find a minimum distance path 
from the source to the destination. Analogous to the real ant, in the algorithm, every artificial ant has a chemical called pheromone. When the ant travels from one place to another, it is left on the path. The path in which density of pheromone is maximum is the shortest path in reality. In the algorithm also this phenomenon is used to find the shortest path for the salesman.

In the algorithm, in the iteration, $t$, an ant $k$, which is currently located at node $i$, selects the next node $j$, depending on a probability, $P_{i j}^{k}(t)$, using some probabilistic selection process, e.g., for Roulette Wheel selection process[15]:

$$
P_{i j}^{k}(t)=\left\{\begin{array}{ccc}
\frac{\tau_{i j}^{\alpha}(t) \eta_{i j}^{\beta}(t)}{\sum_{u \in N_{i}^{k}} \tau_{i u}^{\alpha}(t) \eta_{i u}^{\beta}(t)} & \text { if } \quad j \in N_{i}^{k}(t) \\
0 & \text { if } j \notin N_{i}^{k}(t) .
\end{array}\right.
$$

where $\tau_{i j}$ represents the pheromone value and $\eta_{i j}$ represents the heuristics value of the move from node $i$ to $j$ at time step $t$. $N_{i}^{k}(t)$ represent the set of nodes which are not yet visited by ant $k$ (when it is at node $i$ ). $\alpha$ and $\beta$ are positive real parameters whose values determine the relative importance of the pheromone versus the heuristics information. $\eta_{i j}$ is calculated by following equation,

$$
\eta_{i j}=\frac{1}{d_{i j}}
$$

where $d_{i j}$ is the distance (cost) between the node $i$ and $j$.

Pheromone Evaporation. At the time of visiting the nodes by an ant, some amount of pheromone are evaporated from each edge and some pheromone are deposited on the edges through which the ant move. For each edge $(i, j)$, evaporation takes place using the following rule:

$$
\tau_{i j}(t+1)=\rho \tau_{i j}(t)
$$

with $\rho \in[0,1] . \rho$ is the constant, that specifies pheromone evaporate rate.

Pheromone update rule. After completion of a tour (path) from the source to the destination by all the ants, the pheromone on each edge $(i, j)$ through which any ant moves is updated (due to deposition of pheromone) as

$$
\tau_{i j}(t+1)=\tau_{i j}(t)+\sum_{k=1}^{n_{k}} \triangle \tau_{i j}^{k}(t)
$$

where $\triangle \tau_{i j}^{k}(t)$ is the amount of pheromone deposited by the ant $k$ on the edge $(i, j)$ at time step $t$ and here $\triangle \tau_{i j}^{k}(t)$ is taken as

$$
\triangle \tau_{i j}^{k}(t)=\left\{\begin{array}{lc}
\frac{1}{f\left(X_{k}\right)} & \text { if } \mathrm{k} \text {-th ant passes through the edge }(\mathrm{i}, \mathrm{j}) \\
0 & \text { otherwise }
\end{array}\right.
$$

where $X_{k}$ is the path of $k$-th ant and $f\left(X_{k}\right)$ is the distance of the path. For detail algorithm of ACO please see [10].

\section{K-Opt perturbation Operation for CSP}

K-Opt [26] is mainly used to improve the tour cost of a CSP. It is also called a tour improvement algorithm. The mechanism of K-Opt operation is to break a feasible tour into K-parts, rejoin different permutations of the parts to create different feasible tours and select the best among them for the improvement of the original tour. Here K-Opt operation is applied on a complete tour of a CSP for its possible improvement. For detailed of K-Opt operation, one can refer [11]. 
2-Opt algorithm removes one edge form the tour, and reconnects the two sub-tours' combination and reverses of their path to find the better movement. It is continued until no improvement is found using the process. Similarly in the case of 3-Opt, breaking 2 edges of a tour, eight possible new combinations can be found. In this way we continue to break edges form tour i.e. $\mathrm{K}=1,2,3 \ldots, \mathrm{n}$ and get new algorithm, like 2-Opt, 3-Opt, 4-Opt and so on. But the increase of $K$ increases the time complexity of the algorithm. For that reason, here, the 3-Opt operation is applied and it is found that it acts better than the 2-Opt operation for large size problems.

7.1. $K$-Opt Operation on a complete tour : The detailed algorithm of $K$-Opt operation for $K=3$ is presented below. Here a one-dimension array bestpath $h_{i}$ is used to represent $i$-th path/tour of the CSP obtained using ACO. Then two cities of the path are randomly selected to divide the path into three sub-tour and let these be bestpath $\operatorname{bij}_{i j}, j=1,2,3$. The reverse of these sub-tours are denoted by bestpath ${ }_{i j}^{r}, j=1,2,3$ respectively. Then eight new tours, nbestpath $_{i j}, j=1,2, . .8$, can be formed using bestpath $_{i j}, j=1,2,3$ and bestpath $_{i j}^{r}, j=1,2,3$ as below:

$$
\begin{aligned}
& \text { nbestpath }_{i 1}=\text { bestpath }_{i 1} \rightarrow \text { bestpath }_{i 2} \rightarrow \text { bestpath }_{i 3} \\
& \text { nbestpath }_{i 2}=\text { bestpath }_{i 1} \rightarrow \text { bestpath }_{i 2}^{r} \rightarrow \text { bestpath }_{i 3} \\
& \text { nbestpath }_{i 3}=\text { bestpath }_{i 1} \rightarrow \text { bestpath }_{i 2} \rightarrow \text { bestpath }_{i 3}^{r} \\
& \text { nbestpath }_{i 4}=\text { bestpath }_{i 1} \rightarrow \text { bestpath }_{i 3}^{r} \rightarrow \text { bestpath }_{i 2}^{r} \\
& \text { nbestpath }_{i 5}=\text { bestpath }_{i 1} \rightarrow \text { bestpath }_{i 3} \rightarrow \text { bestpath }_{i 2}^{r} \\
& \text { nbestpath }_{i 6}=\text { bestpath }_{i 1} \rightarrow \text { bestpath }_{i 3}^{r} \rightarrow \text { bestpath }_{i 2} \\
& \text { nbestpath }_{i 7}=\text { bestpath }_{i 1} \rightarrow \text { bestpath }_{i 2}^{r} \rightarrow \text { bestpath }_{i 3}^{r} \\
& \text { nbestpath }_{i 8}=\text { bestpath }_{i 1} \rightarrow \text { bestpath }_{i 3}^{r} \rightarrow \text { bestpath }_{i 2}
\end{aligned}
$$

Among these new tours minimum cost tour is the best found movement using 3-Opt operation once. If cost of this tour is less than the parent tour then it replaces the parent tour.

\section{Proposed algorithm for Covering Salesman problem}

As stated earlier, the proposed algorithm consists of two procedures. The first procedure divides the node set of the problem into groups in such a manner that all the nodes of any group located within the restricted covering distance $r$ (of the problem) from the center of the respective group. The second procedure determines the shortest route through the centres of the group. In the algorithm $N$ represents number of nodes/cities, $N B$ represents number of groups, $N C$ represents maximum number of cities in a group. At first, equal no of nodes are selected in all the groups. The remaining nodes are successively added to different groups depending upon the distance of the node (nearest to the centre element of the group) so that cardinality of a group does not exceed $N C$. $N E$ is the equal number of nodes in each group, i.e., $N E=[N / N B]$, where $[N / N B]$ represents an integral part of $N / N B$. G $[i]$ represents $i$-th group, $l$ is the cardinality of the group, i.e., $G[i] . l$ is the length of group $i$, an array $G[i] . S$ represents the node set of group $i$ and max_iteration is the maximum number of iterations and $N$ is the no of nodes. $\left(d_{i j}\right)_{N \times N}$ represents the distance matrix of the problem.

\section{Start Algorithm}

2. Set $N C, N B$, max_iteration, max_iteration $2, N$.

3. Input $\left(d_{i j}\right)_{N \times N}$

4. For $i=1$ to $m a x \_i t e r a t i o n$ do

5. $\quad$ Set $G[k] . l=0$ for $k=1,2, \ldots, N B$

6. $\quad$ Set $N S=\left\{V_{1}, V_{2}, \ldots V_{N}\right\}$

7. $\quad$ Set $G[i] . S=\{\}$

8. $\quad v_{c}=$ a randomly selected element from $N S$

9. $\quad G[1] . S=G[1] . S \cup\left\{v_{c}\right\}$ 
10. $N S=N S-\left\{v_{c}\right\}$

11. $G[1] . l=G[1] . l+1$

12. For $j=2$ to $N E$ do

13. $v=$ Nearest city of $v_{c}$ in $N S$

14. $G[1] . S=G[1] . S \cup\{v\}$

15. $G[1] . l=G[1] . l+1$

16. $\quad N S=N S-\{v\}$

17. End For

18. For $k=2$ to $N B$ do

19. $v_{c}=$ Nearest city of $v_{c}$ in $N S$

20. $G[k] . S=G[k] . S \cup\left\{v_{c}\right\}$

21. $N S=N S-\left\{v_{c}\right\}$

22. $\quad G[k] . l=G[k] . l+1$

23. For $j=2$ to $N E$ do

24. $v=$ Nearest city of $v_{c}$ in $N S$

25. $G[k] . S=G[k] . S \cup\{v\}$

26. $\quad G[k] . l=G[k] . l+1$

27. $\quad N S=N S-\{v\}$

28. $\quad$ End For

29. End For

30. $\quad$ set count $=0$

31. While $N S \neq\{\}$ do

32. For $k=1$ to $N B$ do

33. If $G[k] . l \leq N C$ then

34. count $=$ count +1

35. $\quad b_{\text {count }}=k$ where $b$ is an array

36. $\quad$ End if

37. $\quad$ End For

38. $\quad v=$ first element from $N S$

39. $N S=N S-\{v\}$

40. $\quad \min =d_{v G\left[b_{1}\right] . S\left[G .\left[b_{1}\right] . l\right]}$

41. $\quad$ pos $=b_{1}$

42. For $k=2$ to count do

43.

44.

45.

46.

47.

48.

49.

50.

$$
\begin{aligned}
& \text { If }\left(d_{\left.v G\left[b_{k}\right] . S\left[G .\left[b_{k}\right] . l\right]<\min \right) \text { then }}\right. \\
& \min =d_{v G\left[b_{k}\right] . S\left[G .\left[b_{k}\right] . l\right]} \\
& \text { pos }=b_{k}
\end{aligned}
$$

\section{End If}

\section{End For}

$G[p o s] . S=G[p o s] . S \cup\{v\}$

$G[p o s] . l=G[p o s] . l+1$

51. For $k=1$ to maxiteration 2 do

52.

53.

54 .

55.

56.

57.

58.

59.

\section{End While}

set $f l a g=0$

For $j=1$ to $N B$ do

$z=$ a randomly selected integer in the range $[1, G[j] . l]$

$G[j]$. center $=G[j] . S[z]$

For $k=1$ to $G[j] . l$ do

If $\left(d_{G[j] . S[k] G[j] . \text { center }}>r\right)$ then flag $=1$

break 


$\begin{array}{lc}60 . & \text { End If } \\ 61 . & \text { End For } \\ 62 . & \text { If flag }=1 \text { then } \\ 63 . & \text { break } \\ 64 . & \text { End If } \\ 65 . & \text { End For } \\ 66 . & \text { if }(\text { flag }=0) \text { then } \\ 67 . & \text { ACO algorithm is used to find the best path according the centres of the groups. } \\ 68 . & \text { K-opt operation is applied on the best path for further possible improvement. } \\ 69 . & \text { The best solution found so far, solution }, \text { is updated. } \\ 70 . & \text { End If } \\ 71 . & \text { End for } \\ 72 . & \text { End for } \\ 73 . & \text { Output solution } \\ 74 . & \text { End algorithm }\end{array}$

8.1. Exploration and exploitation. For any CSP instance, a particular division of the groups of cities and the selection of visiting nodes may converge to local optima. To explore different possible paths, the ACO is applied on the different selections of the set of visiting cities. In this study, $K$-opt operation is applied at the end of the ACO algorithm to avoid convergence of the path at any local optima. If the ACO converges to a local optima, then the application of 3-opt on the obtained path of ACO will find a better path and the repeated application of 3-opt on the improved paths may obtain the global optimal path. In this way, the exploration and exploitation is made in the proposed algorithm.

8.2. Implementation and testing. The algorithm is implemented in $\mathrm{Dev} \mathrm{C}++$ in a computer having Intel core-i3 first generation processor and 2 GB RAM. The algorithm is tested against a set of benchmark test problems from TSPLIB with significantly large sizes (size up to 654 nodes). The performance of the algorithm is compared with different existing successful algorithms for CSP in the literature. It is observed that the efficiency of the proposed algorithm is comparatively better with respect to the other existing algorithms used for the comparison.

\section{Numerical Illustration}

So far the author's knowledge go, in the literature, there is no algorithm that presents results of benchmark CSP instances with specified coverage range $r$. All the studies have been made where groups are created with the nearest nodes from the selected centres of the groups. Due to this reason, here, to measure the efficiency of the proposed algorithm, some standard benchmark test instances are used that are proposed by Golden et al. [7]. These instances are generated form TSPLIB [5]. The test problems have been divided into small, medium, and large size problems according to their sizes. The small size and medium size problems contain 51 to 200 number of nodes where each node can cover nearest 7, 9, 11 number of nodes and the large size problems contain 532 to 654 number of nodes where each node can cover 3, 5, 7 number of nearest nodes. Other notations and symbols are the same as previously stated.

The problems are solved using the proposed algorithm for CSPs and the results are tabulated in Table-1 and table-2. The goal is to minimize the total tour cost of the Hamiltonian path through the visiting nodes. It is observed from the tables that in most of the considered instances tour cost increase with the number of groups, which agrees with reality. In very few cases, the algorithm gives higher tour cost for larger group size, due to the division of the groups. But in those cases also the proposed algorithm gives better results compared to the other well-established 
algorithms used for the comparison. The convergence graphs of the best found solutions for some instances are presented in figure-1.

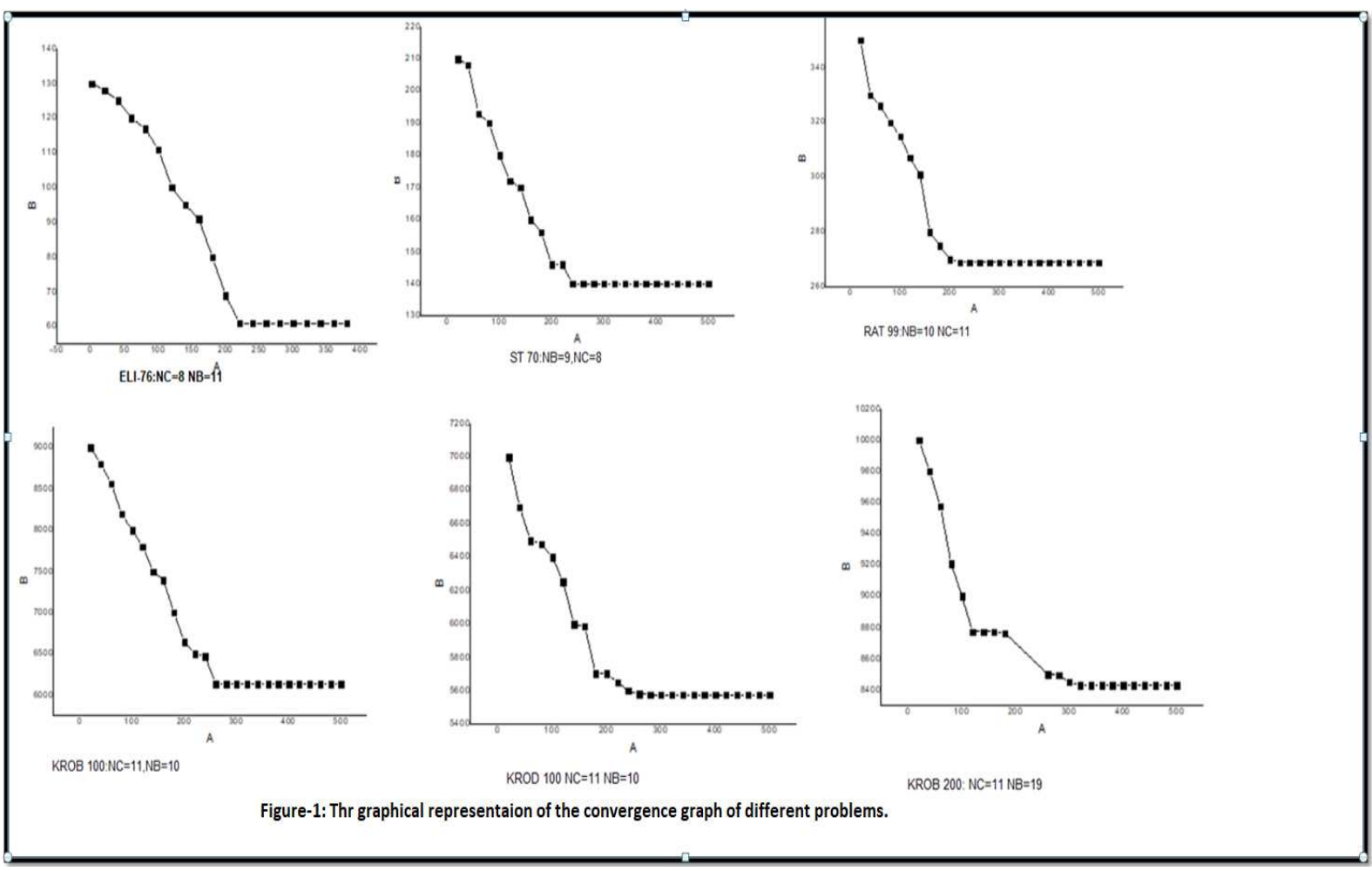

Table- 3 and Table- 4 present the comparative study of the computational results of the proposed algorithm with respect to seven other state-of-the-art algorithms for the CSPs. Table-3 represents the best found cost of the different instances obtained by the different well-established algorithms for CSPs in the literature along with the proposed algorithm. Table-4 represents the average cost and the standard deviation of the results obtained by the different algorithms in five different runs for the different instances. It is observed from the tables that the proposed algorithm obtains the best tour cost as well as the minimum average cost for each of the instances with different numbers of $N C$ s. From these observations, it can be concluded that the efficiency of the proposed algorithm is better compared to the other algorithms in the literature for solving the CSPs.

Table- 5 and Table- 6 present the results due to the different values of the coverage range $r$ for some large size test instances. It is observed from the tables that for each of the instances, the tour cost increases with the decrease of $r$. In Table- 7 also, the results due to the different values of the coverage range $r$ are presented for all the considered test instances. But, here, at first result due to a fixed coverage range, $r$, is obtained, which is presented in the column marking $100 \%$. Then results are obtained by decreasing the coverage range by taking its value $80 \%, 70 \%, 60 \%$ and $50 \%$ of $r$. In some cases, the algorithm could not find any result. In those cases result positions in the table are kept $B L A N K$. It is observed from Table-7 that the tour costs increases gradually as the covering range decreases gradually. Clearly, this observation also agrees with reality.

Again results are obtained for the restricted problems where the Hamiltonian path of a CSP is 
searched under the restriction of a specific coverage range of different groups, i.e., total distance of different cities of a group from the visiting city should not exceed a predefined level. For this study the group coverage range is considered as $N C * r / 3$ for any problem, where the symbols are previously defined and the value of $r$ is mentioned in the table. Results are obtained for different problems and are presented in Table-8. If, for any case, solution does not exists, then the solution position of such problems are kept $B L A N K$ in the table.

As this is the initial study on imprecise CSP, no standard test problems on fuzzy CSP exists in the literature. Due to this reason, test problems with fuzzy cost parameters are generated from the previously considered standard benchmark test problems of CSPs with crisp parameters. To test the proposed algorithm in a fuzzy environment these fuzzy CSPs are used. In a crisp CSP, if travel cost between node $i$ and node $j$ is $d_{i j}$ then following Khan et al. [12, 13], the corresponding fuzzy cost is generated as $\tilde{d}_{i j}=\left(d_{i j 1}, d_{i j 2}, d_{i j 3}\right)$, where $d_{i j 2}=d_{i j}, d_{i j 1}=d_{i j}-R 1$, $d_{i j 3}=d_{i j}+R 2$, where $R 1$ and $R 2$ are randomly generated between $\left(0, R \times d_{i j} / 100\right)$. Here $R$ is the percentage of fuzziness and its value is considered as 0.5 , i.e., here, maximum $0.5 \%$ fuzziness is considered for the fuzzy costs. Table-9 presents the computational results of these problems using the proposed algorithm in fuzzy environment. As cost matrices are generated with $0.5 \%$ fuzziness the tour costs of the best found paths are near to the corresponding crisp problems and it implies that the proposed algorithm is efficient enough to solve CSPs with fuzzy cost matrices. Results are obtained following both the direct credibility measure approach and the simulation approach for the same and the same results are obtained. As a result only one result table is presented, as, the same results are obtained using two approaches.

Due to the same reason as the fuzzy CSPs, there are no standard test problems on rough CSPs in the literature. Due to this reason, test problems with rough cost parameters are generated from the previously considered standard benchmark test problems of CSPs with crisp parameters. To test the proposed algorithm in a rough environment these generated CSPs with rough cost parameters are used. If in a crisp CSP, travel cost between node $i$ and node $j$, is $d_{i j}$, then following Khan et al. [13], the corresponding cost in the rough environment is generated as $\tilde{d}_{i j}=\left(d_{i j 1}, d_{i j 2}, d_{i j 3}, d_{i j 4}\right)$, where $d_{i j 1}=d_{i j}, d_{i j 2}=d_{i j}+R 1, d_{i j 3}=d_{i j}-R 2, d_{i j 3}=d_{i j 1}+R 3$ and $R 1, R 2, R 3$ are randomly generated in $\left(0, R \times d_{i j} / 100\right)$. Here $R$ is the percentage of roughness and its value is considered as 0.5 , i.e., here maximum $0.5 \%$ roughness is considered for the rough costs. Table-10 presents the computational results of these problems using the proposed algorithm in rough environment. As cost matrices are generated with $0.5 \%$ roughness the tour costs of the best found paths are near to the corresponding crisp problems and it implies that the proposed algorithm is efficient enough to solve CSPs with rough cost matrices. Results are obtained following both the direct trust measure approach and the simulation approach and the same results are obtained. As a result only one result table is presented, as, the same results are obtained using two approaches.

\section{Conclusion}

Here for the first time, the ACO algorithm is modified with $K$-opt operation to develop an efficient and consistent algorithm for CSPs under one restriction in crisp and imprecise (fuzzy, rough) environments. An algorithm is proposed for the division of groups of the cities depending upon the maximum number of cities in a group and the total number of groups. The ACO is used to find the shortest/minimum-cost path of any problem by selecting only one city from each group in such a manner that all the unvisited cities are within a predefined coverage range $r$. $K$-opt algorithm is used at the end of ACO operation for the possible improvement of the quality of the solution. Here, study is made only in two imprecise environments- fuzzy environment and rough environment. To solve the problem in imprecise environment some approach is followed 
where tour is searched without transferring the imprecise optimisation problem into a crisp optimisation problem. Moreover, fuzzy and rough simulation approaches are proposed to solve the problem for type of fuzzy data set and any measure of rough data set. For the restricted problems path are searched in such a manner that the total distance/cost of different cities of a group from the visited city of the group should not exceed a predefined limit. The algorithm is tested with standard benchmark crisp problems available in the literature. To test the algorithm in the imprecise environment, imprecise instances are derived randomly from the standard crisp instances using a specified rule. Different numerical studies and the comparison studies with different well-established algorithms for CSPs establish the efficiency of the proposed approach for solving the CSPs in the crisp as well as in the imprecise environments. The approaches presented in this study is applicable in any routing problems, like, TSP, GTSP, CTP, BCSP, Vehicle Routing Problem, etc., in different environments. The simulation approaches presented here can be applied to solve different real life optimisation problems in science and technology. In future work, stochastic simulation approach can be used to deal with the problem with the random data sets. Also, the study can be done with the mixed data sets, i.e., the data sets involving different types of imprecise data. Multi-objective CSPs in imprecise environments can also be studied in the future. 
Table-1: The computational results of the proposed algorithm

\begin{tabular}{|c|c|c|c|c|c|c|c|c|}
\hline Instance & $\mathrm{NC}$ & \multicolumn{7}{|c|}{ Best found tour cost } \\
\hline \multirow{6}{*}{ berlin 52} & \multirow[b]{2}{*}{7} & NB & 8 & 9 & 10 & 11 & 12 & 13 \\
\hline & & Best cost & 1459 & 1540 & 2157 & 1639 & 2361 & 2607 \\
\hline & \multirow[b]{2}{*}{9} & NB & 6 & 7 & 8 & 9 & 10 & 11 \\
\hline & & Best cost & 1112 & 1180 & 1455 & 1528 & 2157 & 1647 \\
\hline & \multirow[b]{2}{*}{11} & NB & 5 & 6 & 7 & 8 & 9 & 10 \\
\hline & & Best cost & 1029 & 953 & 1122 & 1455 & 1547 & 2157 \\
\hline \multirow{6}{*}{ st70 } & \multirow[b]{2}{*}{7} & NB & 10 & 11 & 12 & 13 & 14 & 15 \\
\hline & & Best cost & 172 & 185 & 205 & 212 & 235 & 243 \\
\hline & \multirow[b]{2}{*}{9} & NB & 8 & 9 & 10 & 11 & 12 & 13 \\
\hline & & Best cost & 140 & 158 & 176 & 181 & 204 & 222 \\
\hline & \multirow[b]{2}{*}{11} & NB & 7 & 8 & 9 & 10 & 11 & 12 \\
\hline & & Best cost & 108 & 131 & 164 & 176 & 181 & 201 \\
\hline \multirow{6}{*}{ eil76 } & \multirow[b]{2}{*}{7} & NB & 11 & 12 & 13 & 14 & 15 & 16 \\
\hline & & Best cost & 118 & 130 & 139 & 147 & 152 & 155 \\
\hline & \multirow[b]{2}{*}{9} & NB & 9 & 10 & 11 & 12 & 13 & 14 \\
\hline & & Best cost & 90 & 93 & 115 & 125 & 140 & 152 \\
\hline & \multirow[b]{2}{*}{11} & NB & 7 & 8 & 9 & 10 & 11 & 12 \\
\hline & & Best cost & 62 & 61 & 89 & 108 & 109 & 125 \\
\hline \multirow{6}{*}{ rat99 } & \multirow[b]{2}{*}{7} & NB & 15 & 16 & 17 & 18 & 19 & 20 \\
\hline & & Best cost & 382 & 400 & 386 & 411 & 439 & 428 \\
\hline & \multirow[b]{2}{*}{9} & NB & 12 & 13 & 14 & 15 & 16 & 17 \\
\hline & & Best cost & 201 & 341 & 359 & 392 & 404 & 377 \\
\hline & \multirow[b]{2}{*}{11} & NB & 10 & 11 & 12 & 13 & 14 & 15 \\
\hline & & Best cost & 269 & 313 & 332 & 327 & 365 & 379 \\
\hline \multirow{6}{*}{ kroA100 } & \multirow[b]{2}{*}{7} & NB & 15 & 16 & 17 & 18 & 19 & 20 \\
\hline & & Best cost & 7365 & 7857 & 7760 & 8347 & 8774 & 9349 \\
\hline & \multirow[b]{2}{*}{9} & NB & 12 & 13 & 14 & 15 & 16 & 17 \\
\hline & & Best cost & 6641 & 6236 & 7616 & 7804 & 8150 & 7772 \\
\hline & & NB & 10 & 11 & 12 & 13 & 14 & 15 \\
\hline & 11 & Best cost & 5651 & 6485 & 6460 & 6293 & 7616 & 7741 \\
\hline & & NB & 15 & 16 & 17 & 18 & 19 & 20 \\
\hline & 7 & Best cost & 7538 & 8341 & 8180 & 8676 & 9268 & 9147 \\
\hline & & NB & 12 & 13 & 14 & 15 & 16 & 17 \\
\hline kroB100 & 9 & Best cost & 6816 & 6913 & 7597 & 7975 & 8426 & 8013 \\
\hline & & NB & 10 & 11 & 12 & 13 & 14 & 15 \\
\hline & 11 & Best cost & 6135 & 6349 & 6463 & 7216 & 7597 & 7366 \\
\hline & & NB & 15 & 16 & 17 & 18 & 19 & 20 \\
\hline & 7 & Best cost & 7272 & 7543 & 7864 & 8173 & 8644 & 8795 \\
\hline & & NB & 12 & 13 & 14 & 15 & 16 & 17 \\
\hline kroC100 & 9 & Best cost & 6349 & 6825 & 7317 & 7206 & 7612 & 7847 \\
\hline & & NB & 10 & 11 & 12 & 13 & 14 & 15 \\
\hline & 11 & Best cost & 5851 & 6422 & 6515 & 6705 & 7484 & 7366 \\
\hline & & NB & 15 & 16 & 17 & 18 & 19 & 20 \\
\hline & 7 & Best cost & 6866 & 8032 & 8030 & 8647 & 9084 & 9221 \\
\hline & & NB & 12 & 13 & 14 & 15 & 16 & 17 \\
\hline kroD100 & 9 & Best cost & 6595 & 6846 & 7778 & 7176 & 7538 & 7924 \\
\hline & & NB & 10 & 11 & 12 & 13 & 14 & 15 \\
\hline & 11 & Best cost & 5575 & 6088 & 6026 & 6890 & 7517 & 7237 \\
\hline
\end{tabular}


Table-2: The computational results of the proposed algorithm \begin{tabular}{l|l|l} 
Instance & $\mathrm{NC}$ & Best found tour cost
\end{tabular} 
Table-3: Performance study of the proposed algorithm with respect to different algorithms for CSP

Table-3 Continued.

\begin{tabular}{|c|c|c|c|c|c|c|c|c|}
\hline \multirow{3}{*}{ Instance } & \multirow{2}{*}{ NC } & \multicolumn{7}{|c|}{ Bable-3 Continued. } \\
\cline { 3 - 10 } & & $\begin{array}{c}\text { LS2 } \\
{[7]}\end{array}$ & $\begin{array}{c}\text { ILP } \\
{[24]}\end{array}$ & $\begin{array}{c}\text { Hybrid } \\
\text { ACO }[25]\end{array}$ & $\begin{array}{c}\text { Hybrid } \\
\text { ABC }[22]\end{array}$ & $\begin{array}{c}\text { Hybrid } \\
\text { GA }[22]\end{array}$ & $\begin{array}{c}\text { PVNS } \\
{[31]}\end{array}$ & $\begin{array}{c}\text { Proposed } \\
\text { Algorithm }\end{array}$ \\
\hline \multirow{4}{*}{ att532 } & 3 & 52399 & 52412 & 51616 & - & - & 51457 & $\mathbf{5 0 6 8 4}$ \\
\cline { 2 - 10 } & 5 & 42634 & 42387 & 42212 & - & - & 42148 & $\mathbf{4 0 9 5 0}$ \\
\cline { 2 - 10 } & 7 & 38186 & 38016 & 37741 & 37608 & 37506 & 37621 & $\mathbf{3 5 9 2 8}$ \\
\hline \multirow{3}{*}{ ali535 } & 3 & 1370 & 1368 & 1367 & 1370 & 1369 & 1365 & $\mathbf{1 2 6 2}$ \\
\cline { 2 - 9 } & 5 & 1184 & 1206 & 1185 & 1187 & 1182 & 1183 & $\mathbf{1 0 3 4}$ \\
\cline { 2 - 9 } & 7 & 1094 & 1086 & 1083 & 1084 & 1079 & 1079 & $\mathbf{9 0 0}$ \\
\hline & 3 & 25158 & 25155 & 25166 & 25186 & 25119 & 25181 & $\mathbf{2 3 5 3 7}$ \\
\cline { 2 - 9 } & 5 & 23226 & 23211 & 23242 & 23285 & 23205 & 23224 & $\mathbf{2 0 6 6 9}$ \\
\cline { 2 - 9 } & 7 & 22121 & 22126 & 22125 & 22121 & 22118 & 22135 & $\mathbf{2 0 4 4 4}$ \\
\hline
\end{tabular}




\begin{tabular}{|c|c|c|c|c|c|c|c|c|c|c|c|c|c|c|c|}
\hline & & \multicolumn{2}{|c|}{ LS2[7] } & \multicolumn{2}{|c|}{$\operatorname{ILP}[24]$} & \multicolumn{2}{|c|}{ Hybrid ACO[25] } & \multicolumn{2}{|c|}{ Hybrid GA[22] } & \multicolumn{2}{|c|}{ Hybrid ABC[22] } & \multicolumn{2}{|c|}{ PVNS[31] } & \multicolumn{2}{|c|}{ Proposed Algorithm } \\
\hline \multirow{3}{*}{ berlin 52} & 7 & 3887 & 0.0 & 3887 & 0.0 & 3887.4 & 0.01 & 3887 & 0.0 & 3887 & 0.0 & 3887 & 0.0 & 1459 & 0.0 \\
\hline & 9 & 3430 & 0.0 & 3430 & 0.0 & 3430 & 0.0 & 3430 & 0.0 & 3430 & 0.0 & 3430 & 0.0 & 1112 & 0.0 \\
\hline & 11 & 3262 & 0.0 & 3262 & 0.0 & 3262 & 0.0 & 3262 & 0.0 & 3262 & 0.0 & 3262 & 0.0 & 1029 & 0.0 \\
\hline \multirow{3}{*}{ st70 } & 7 & 288 & 0.0 & 288 & 0.0 & 288 & 0.0 & 288 & 0.0 & 288 & 0.0 & 288 & 0.0 & 176 & 0.0 \\
\hline & 9 & 259 & 0.0 & 259 & 0.0 & 259 & 0.0 & 259 & 0.0 & 259 & 0.0 & 259 & 0.0 & 140 & 0.0 \\
\hline & 11 & 247 & 0.0 & 247 & 0.0 & 247 & 0.0 & 247 & 0.0 & 247 & 0.0 & 247 & 0.0 & 108 & 0.0 \\
\hline \multirow{3}{*}{ eil76 } & 7 & 207 & 0.0 & 207 & 0.0 & 207 & 0.0 & 207 & 0.0 & 207 & 0.0 & 211 & 0.0 & 118 & 0.0 \\
\hline & 9 & 186 & 0.54 & 185 & 0.0 & 186 & 0.54 & 185 & 0.0 & 186 & 0.54 & 185 & 0.0 & 90 & 0.0 \\
\hline & 11 & 170 & 0.0 & 170 & 0.0 & 170 & 0.0 & 170 & 0.0 & 170 & 0.0 & 170 & 0.0 & 61 & 0.0 \\
\hline \multirow{3}{*}{ rat99 } & 7 & 486 & 0.0 & 486 & 0.0 & 486 & 0.0 & 486 & 0.0 & 486 & 0.0 & 486 & 0.0 & 382 & 0.0 \\
\hline & 9 & 455 & 0.0 & 455 & 0.0 & 455 & 0.0 & 455 & 0.0 & 455 & 0.0 & 455 & 0.0 & 201 & 0.0 \\
\hline & 11 & 444 & 0.0 & 444 & 0.0 & 444 & 0.0 & 444 & 0.0 & 444 & 0.0 & 444 & 0.0 & 269 & 0.0 \\
\hline \multirow{3}{*}{ kroA100 } & 7 & 9674 & 0.0 & 9674 & 0.0 & 9674 & 0.0 & 9674 & 0.0 & 9674 & 0.0 & 9674 & 0.0 & 7363.2 & 0.6 \\
\hline & 9 & 9159 & 0.0 & 9159 & 0.0 & 9159 & 0.0 & 9159 & 0.0 & 9159 & 0.0 & 9159 & 0.0 & 6236.2 & 0.5 \\
\hline & 11 & 8901 & 0.0 & 8901 & 0.0 & 8901 & 0.0 & 8901 & 0.0 & 8901 & 0.0 & 8901 & 0.0 & 5651.2 & 0.5 \\
\hline \multirow{3}{*}{ kroB100 } & 7 & 9537 & 0.0 & 9537 & 0.0 & 9537 & 0.0 & 9537 & 0.0 & 9537 & 0.0 & 9537 & 0.0 & 7538.2 & 0.7 \\
\hline & 9 & 9240 & 0.0 & 9240 & 0.0 & 9240 & 0.0 & 9240 & 0.0 & 9240 & 0.0 & 9240 & 0.0 & 6693.2 & 0.6 \\
\hline & 11 & 8842 & 0.0 & 8842 & 0.0 & 8842 & 0.0 & 8842 & 0.0 & 8842 & 0.0 & 8842 & 0.0 & 6135.3 & 0.9 \\
\hline \multirow{3}{*}{ kroC100 } & 7 & 9723 & 0.0 & 9723 & 0.0 & 9724 & 0.01 & 9723 & 0.0 & 9723 & 0.0 & 9723 & 0.0 & 7272.2 & 0.8 \\
\hline & 9 & 9171 & 0.0 & 9171 & 0.0 & 9171 & 0.0 & 9171 & 0.0 & 9171 & 0.0 & 9171 & 0.0 & 6349.2 & 0.6 \\
\hline & 11 & 8632 & 0.0 & 8632 & 0.0 & 8632 & 0.0 & 8632 & 0.0 & 8632 & 0.0 & 8632 & 0.0 & 5821.3 & 0.4 \\
\hline \multirow{3}{*}{ kroE100 } & 7 & 10150 & 0.0 & 10150 & 0.0 & 10150 & 0.0 & 10150 & 0.0 & 10150 & 0.0 & 10150 & 0.0 & 7407.2 & 0.5 \\
\hline & 9 & 8991 & 0.0 & 8991 & 0.0 & 8991 & 0.0 & 8991 & 0.0 & 8992 & 0.0 & 8991 & 0.0 & 6709.3 & 0.8 \\
\hline & 11 & 8450 & 0.0 & 8450 & 0.0 & 8450 & 0.0 & 8450 & 0.0 & 8450 & 0.0 & 8450 & 0.0 & 6287.2 & 0.5 \\
\hline \multirow{3}{*}{ kroA150 } & 7 & 11800 & 3.30 & 11423.00 & 0.0 & 11423 & 0.0 & 11423 & 0.0 & 11423 & 0.0 & 11423 & 0.0 & 9220.3 & 0.4 \\
\hline & 9 & 10062.4 & 0.06 & 10057.6 & 0.02 & 10056 & 0.0 & 10056 & 0.0 & 10057 & 0.02 & 10056 & 0.0 & 8106.2 & 0.5 \\
\hline & 11 & 9439 & 0.0 & 9439 & 0.0 & 9439 & 0.0 & 9439 & 0.0 & 9439 & 0.0 & 9439 & 0.0 & 7408.5 & 0.9 \\
\hline \multirow{3}{*}{ kroA200 } & 7 & 13666.4 & 2.87 & 13327 & 0.32 & 13286 & 0.01 & 13285 & 0.0 & 13286 & 0.01 & 13286 & 0.01 & 10783.3 & 0.6 \\
\hline & 9 & 11716.8 & 0.08 & 11731.6 & 0.20 & 11710 & 0.02 & 11708 & 0.0 & 11708 & 0.0 & 11710 & 0.02 & 8994.3 & 0.6 \\
\hline & 11 & 10848.6 & 1.94 & 10865.6 & 1.09 & 10764.2 & 0.15 & 10748 & 0.0 & 10748 & 0.0 & 10761.2 & 0.12 & 8432.2 & 0.5 \\
\hline \multirow{3}{*}{ ali535 } & 3 & 1387.0 & 1.46 & 1381.4 & 1.05 & 1370.0 & 0.22 & 1375.8 & 0.64 & 1384.0 & 1.24 & 1370 & 0.37 & 712.75 & 2.83 \\
\hline & 5 & 1201.2 & 1.62 & 1210.2 & 2.39 & 1188.4 & 0.54 & 1190.6 & 0.73 & 1189.8 & 0.66 & 1188.4 & 0.46 & 792.61 & 2.17 \\
\hline & 7 & 1103.6 & 2.09 & 1093.4 & 1.15 & 1084.2 .2 & 0.30 & 1088.4 & 0.68 & 1082.8 & 0.17 & 1084.2 & 0.48 & 664.46 & 1.63 \\
\hline \multirow{3}{*}{ p654 } & 3 & 25206.6 & .32 & 25206.0 & 0.31 & 25182.8 & 0.22 & 25224.2 & 0.39 & 25133.4 & 0.03 & 25219.4 & 0.26 & 19921.75 & 2.54 \\
\hline & 5 & 23258.4 & 0.23 & 23224.8 & 0.09 & 23289.4 & 0.36 & 23291 & 0.37 & 23215.6 & 0.05 & 23278.4 & 0.29 & 20250.625 & 2.24 \\
\hline & 7 & 22233.4 & 0.52 & 22138.6 & .09 & 22130.8 & 0.06 & 22125.2 & 0.3 & 22119.6 & 0.01 & 22141.2 & 0.07 & 19381.75 & 2.54 \\
\hline
\end{tabular}


Table-5: The computational results due to different coverage range $(r)$

\begin{tabular}{|c|c|c|c|c|c|c|c|c|c|c|c|c|c|c|c|c|c|}
\hline Instance & $\mathrm{NC}$ & & & & & Best & our co & found & or dif & rent $\mathrm{N}$ & and $\mathrm{c}$ & verage & ange $r$ & & & & \\
\hline \multirow{9}{*}{ berlin 52} & \multirow[b]{3}{*}{7} & NB & \multicolumn{3}{|c|}{8} & \multicolumn{3}{|c|}{9} & \multicolumn{3}{|c|}{10} & \multicolumn{3}{|c|}{11} & \multicolumn{3}{|c|}{12} \\
\hline & & $r$ & 500 & 600 & 700 & 500 & 600 & 700 & 500 & 600 & 700 & 500 & 600 & 700 & 500 & 600 & 700 \\
\hline & & result & 2607 & 2198 & 1844 & 2782 & 2115 & 1913 & 3089 & 2867 & 2518 & 3166 & 2342 & 2102 & 3368 & 2698 & 2382 \\
\hline & \multirow[b]{3}{*}{9} & NB & \multicolumn{3}{|c|}{8} & & 9 & & & 10 & & & 11 & & & 12 & \\
\hline & & $r$ & 500 & 600 & 700 & 500 & 600 & 700 & 500 & 600 & 700 & 500 & 600 & 700 & 500 & 600 & 700 \\
\hline & & result & 2560 & 2040 & 2008 & 2692 & 2328 & 1985 & 3089 & 2867 & 2518 & 2977 & 2445 & 2129 & 3152 & 2636 & 2426 \\
\hline & & NB & & 7 & & & 8 & & & 9 & & & 10 & & & 11 & \\
\hline & & $r$ & 500 & 600 & 700 & 500 & 600 & 700 & 500 & 600 & 700 & 500 & 600 & 700 & 500 & 600 & 700 \\
\hline & 11 & result & 2547 & 2094 & 1808 & 2597 & 2040 & 1993 & 2692 & 2316 & 1985 & 3089 & 2867 & 2518 & 2977 & 2474 & 2089 \\
\hline & & NB & & 10 & & & 11 & & & 12 & & & 13 & & & 14 & \\
\hline & & $r$ & 50 & 90 & 100 & 50 & 90 & 100 & 50 & 90 & 100 & 50 & 90 & 100 & 50 & 90 & 100 \\
\hline & 7 & result & 205 & 185 & 182 & 211 & 181 & 198 & 216 & 204 & 206 & 230 & 224 & 223 & 238 & 235 & 235 \\
\hline & & NB & & 8 & & & 9 & & & 10 & & & 11 & & & 12 & \\
\hline & & $r$ & 50 & 90 & 100 & 50 & 90 & 100 & 50 & 90 & 100 & 50 & 90 & 100 & 50 & 90 & 100 \\
\hline st70 & 9 & result & 169 & 143 & 142 & 187 & 157 & 167 & 205 & 185 & 182 & 202 & 193 & 190 & 214 & 205 & 202 \\
\hline & & NB & & 7 & & & 8 & & & 9 & & & 10 & & & 11 & \\
\hline & & $r$ & 50 & 90 & 100 & 50 & 90 & 100 & 50 & 90 & 100 & 50 & 90 & 100 & 50 & 90 & 100 \\
\hline & 11 & result & 162 & 131 & 123 & 153 & 143 & 150 & 178 & 161 & 157 & 202 & 185 & 182 & 202 & 193 & 190 \\
\hline & & NB & & 11 & & & 12 & & & 13 & & & 14 & & & 15 & \\
\hline & & $r$ & 30 & 40 & 50 & 30 & 40 & 50 & 30 & 40 & 50 & 30 & 40 & 50 & 30 & 40 & 50 \\
\hline & 7 & result & 156 & 130 & 123 & 132 & 129 & 132 & 147 & 143 & 155 & 142 & 142 & 142 & 156 & 157 & 157 \\
\hline & & $\mathrm{NB}$ & & 9 & & & 10 & & & 11 & & & 12 & & & 13 & \\
\hline & & $r$ & 30 & 40 & 50 & 30 & 40 & 50 & 30 & 40 & 50 & 30 & 40 & 50 & 30 & 40 & 50 \\
\hline eil76 & 9 & result & 117 & 93 & 90 & 122 & 102 & 98 & 122 & 120 & 118 & 132 & 132 & 128 & 145 & 134 & 134 \\
\hline & & NB & & 7 & & & 8 & & & 9 & & & 10 & & & 11 & \\
\hline & & $r$ & 30 & 40 & 50 & 30 & 40 & 50 & 30 & 40 & 50 & 30 & 40 & 50 & 30 & 40 & 50 \\
\hline & 11 & result & 117 & 88 & 68 & 112 & 83 & 78 & 107 & 97 & 85 & 118 & 102 & 93 & 126 & 115 & 111 \\
\hline & & $r$ & 1000 & 1100 & 1200 & 1000 & 1100 & 1200 & 1000 & 1100 & 1200 & 1000 & 1100 & 1200 & 1000 & 1100 & 1200 \\
\hline & 7 & result & 8054 & 8202 & 8056 & 8840 & 8766 & 8639 & 9408 & 8917 & 8917 & 9339 & 9189 & 8903 & 10594 & 10131 & 9532 \\
\hline & & NB & & 12 & & & 13 & & & 14 & & & 15 & & & 16 & \\
\hline & & $r$ & 1000 & 1100 & 1200 & 1000 & 1100 & 1200 & 1000 & 1100 & 1200 & 1000 & 1100 & 1200 & 1000 & 1100 & 1200 \\
\hline kroA100 & 9 & result & 8859 & 7903 & 7748 & 8289 & 8174 & 7857 & 8401 & 8165 & 8077 & 8130 & 8018 & 7966 & 8241 & 8349 & 8201 \\
\hline & & NB & & 10 & & & 11 & & & 12 & & & 13 & & & 14 & \\
\hline & & $r$ & 1000 & 1100 & 1200 & 1000 & 1100 & 1200 & 1000 & 1100 & 1200 & 1000 & 1100 & 1200 & 1000 & 1100 & 1200 \\
\hline & 11 & result & 7827 & 7552 & 7552 & 7785 & 7646 & 7170 & 7814 & 7801 & 7631 & 8220 & 7753 & 7770 & 8401 & 8165 & 8077 \\
\hline & & NB & & 16 & & & 17 & & & 18 & & & 19 & & & 20 & \\
\hline & & $r$ & 1000 & 1100 & 1200 & 1000 & 1100 & 1200 & 1000 & 1100 & 1200 & 1000 & 1100 & 1200 & 1000 & 1100 & 1200 \\
\hline & 7 & result & 8285 & 8090 & 8090 & 8647 & 8671 & 8344 & 8690 & 8690 & 8250 & 9079 & 8771 & 8771 & 9585 & 9175 & 9071 \\
\hline & & NB & & 12 & & & 13 & & & 14 & & & 15 & & & 16 & \\
\hline & & $r$ & 1000 & 1100 & 1200 & 1000 & 1100 & 1200 & 1000 & 1100 & 1200 & 1000 & 1100 & 1200 & 1000 & 1100 & 1200 \\
\hline kroC100 & 9 & result & 7415 & 7510 & 7415 & 7794 & 7747 & 7173 & 7954 & 7927 & 7801 & 7947 & 7553 & 7553 & 8360 & 8050 & 7846 \\
\hline & & NB & & 10 & & & 11 & & & 12 & & & 13 & & & 14 & \\
\hline & & $r$ & 1000 & 1100 & 1200 & 1000 & 1100 & 1200 & 1000 & 1100 & 1200 & 1000 & 1100 & 1200 & 1000 & 1100 & 1200 \\
\hline & 11 & result & 7138 & 6937 & 6890 & 7110 & 7034 & 6917 & 7494 & 7319 & 7419 & 7822 & 7473 & 7126 & 7954 & 7927 & 7573 \\
\hline & & NB & & 16 & & & 17 & & & 18 & & & 19 & & & 20 & \\
\hline & & $r$ & 1000 & 1100 & 1200 & 1000 & 1100 & 1200 & 1000 & 1100 & 1200 & 1000 & 1100 & 1200 & 1000 & 1100 & 1200 \\
\hline & 7 & result & 8422 & 8341 & 8169 & & 9130 & 8431 & 9717 & 9083 & 8828 & 9426 & 8559 & 8959 & 9754 & 9346 & 9251 \\
\hline & & NB & & 12 & & & 13 & & & 14 & & & 15 & & & 16 & \\
\hline & & $r$ & 1000 & 1100 & 1200 & 1000 & 1100 & 1200 & 1000 & 1100 & 1200 & 1000 & 1100 & 1200 & 1000 & 1100 & 1200 \\
\hline kroD100 & 9 & result & 8263 & 7784 & 7093 & 7919 & 7911 & 7441 & 8018 & 8033 & 7783 & 8587 & 7917 & 7817 & 8202 & 8202 & 8202 \\
\hline & & NB & & 10 & & & 11 & & & 12 & & & 13 & & & 14 & \\
\hline & & $r$ & 1000 & 1100 & 1200 & 1000 & 1100 & 1200 & 1000 & 1100 & 1200 & 1000 & 1100 & 1200 & 1000 & 1100 & 1200 \\
\hline & 11 & result & 7410 & 6906 & 6645 & 7346 & 6776 & 6776 & 8015 & 7779 & 7298 & 7437 & 7335 & 7335 & 8018 & 8018 & 7783 \\
\hline & & $r$ & 1000 & 1100 & 1200 & 1000 & 1100 & 1200 & 1000 & 1100 & 1200 & 1000 & 1100 & 1200 & 1000 & 1100 & 1200 \\
\hline & 7 & result & 8436 & 8330 & 7860 & 8875 & 8877 & 8525 & 9152 & 8985 & 8769 & 9157 & 8775 & 9589 & 9580 & 9422 & 9422 \\
\hline & & NB & & 12 & & & 13 & & & 14 & & & 15 & & & 16 & \\
\hline & & $r$ & 1000 & 1100 & 1200 & 1000 & 1100 & 1200 & 1000 & 1100 & 1200 & 1000 & 1100 & 1200 & 1000 & 1100 & 1200 \\
\hline kroE100 & 9 & result & 8263 & 7784 & 7093 & 7919 & 7911 & 7441 & 8018 & 8033 & 7783 & 8587 & 7917 & 7817 & 8202 & 8202 & 8202 \\
\hline & & NB & & 10 & & & 11 & & & 12 & & & 13 & & & 14 & \\
\hline & & $r$ & 1000 & 1100 & 1200 & 1000 & 1100 & 1200 & 1000 & 1100 & 1200 & 1000 & 1100 & 1200 & 1000 & 1100 & 1200 \\
\hline & 11 & result & 7040 & 6951 & 6752 & 7409 & 7200 & 6911 & 7551 & 7513 & 7513 & 7920 & 7370 & 7220 & 8283 & 7651 & 7651 \\
\hline
\end{tabular}


Table-5 Continued.

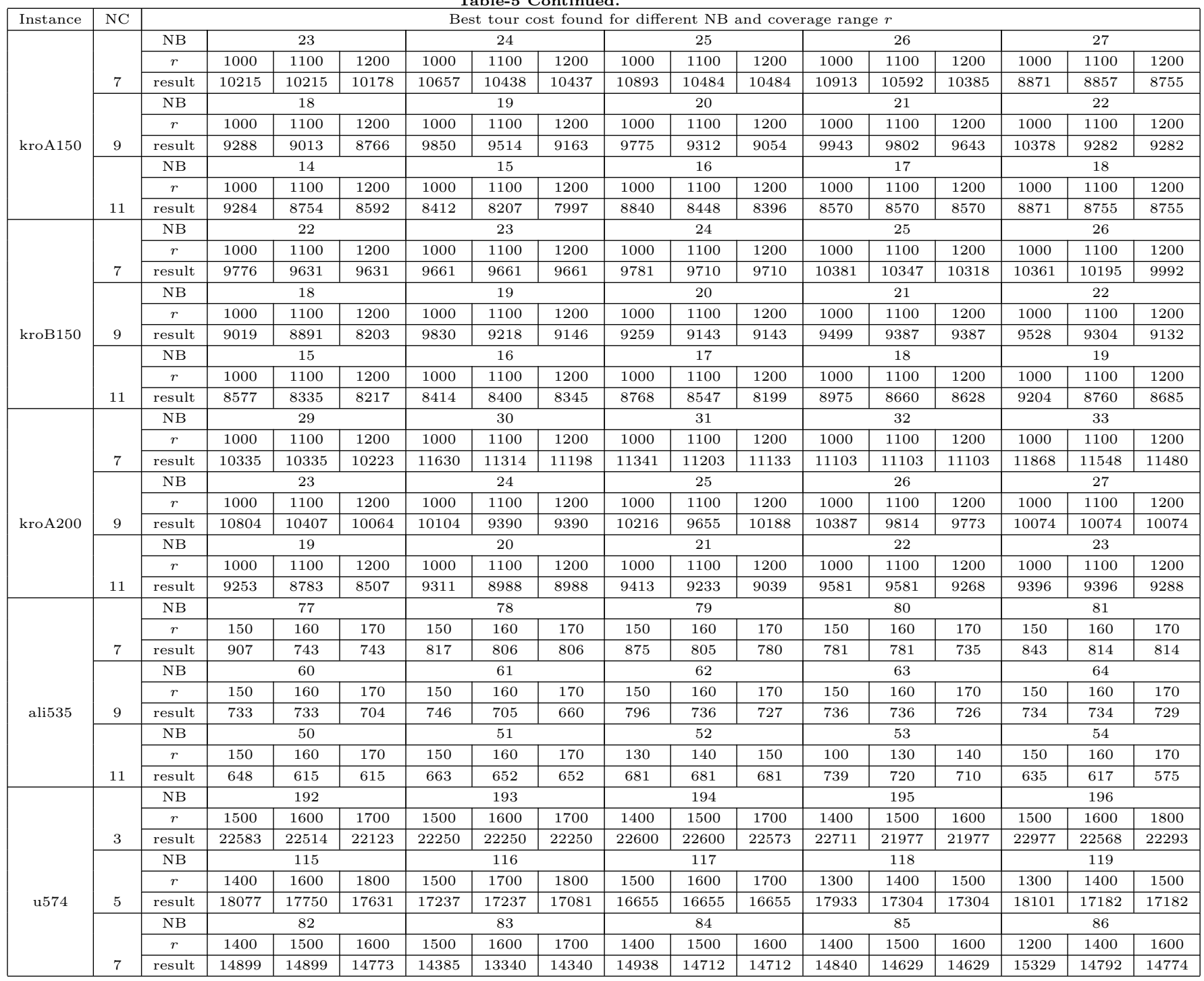


Table-6: The computational results due to different coverage range $(r)$ 
Table-6 continued

\begin{tabular}{|c|c|c|c|c|c|c|c|c|c|c|c|c|c|c|c|c|c|}
\hline Instance & $\mathrm{NC}$ & \multirow{2}{*}{\multicolumn{6}{|c|}{$15(r=2233)$}} & \multicolumn{10}{|c|}{ est tour cost found for different NB } \\
\hline \multirow{18}{*}{ kroB100 } & \multirow{6}{*}{7} & & & & & & & & & $(r=24$ & & & & & $(r=25$ & & \\
\hline & & size & $50 \%$ & $60 \%$ & $70 \%$ & $80 \%$ & $100 \%$ & $50 \%$ & $60 \%$ & $70 \%$ & $80 \%$ & $100 \%$ & $50 \%$ & $60 \%$ & $70 \%$ & $80 \%$ & $100 \%$ \\
\hline & & result & 8664 & 8343 & 8343 & 8051 & 7538 & 8534 & 8534 & 8585 & 8365 & 8341 & 9158 & 8227 & 8177 & 7822 & 8180 \\
\hline & & NB & & & $(r=22$ & & & & & $(r=12$ & & & & & $(r=15$ & & \\
\hline & & size & $50 \%$ & $60 \%$ & $70 \%$ & $80 \%$ & $100 \%$ & $50 \%$ & $60 \%$ & $70 \%$ & $80 \%$ & $100 \%$ & $50 \%$ & $60 \%$ & $70 \%$ & $80 \%$ & $100 \%$ \\
\hline & & result & 9003 & 8822 & 8773 & 8659 & 8659 & - & 11177 & 9898 & 9227 & 9227 & 10846 & 10014 & 9684 & 9544 & 9147 \\
\hline & & NB & & & $r=11$ & & & & & $(r=14$ & & & & & $r=18$ & & \\
\hline & & size & $50 \%$ & $60 \%$ & $70 \%$ & $80 \%$ & $100 \%$ & $50 \%$ & $60 \%$ & $70 \%$ & $80 \%$ & $100 \%$ & $50 \%$ & $60 \%$ & $70 \%$ & $80 \%$ & $100 \%$ \\
\hline & 9 & result & 7004 & 7009 & 6839 & 6729 & 6729 & - & 9968 & 8203 & 7423 & 6913 & 8832 & 7927 & 8066 & 7614 & 7597 \\
\hline & & NB & & & $(r=24$ & & & & & $(r=19$ & & & & & $(r=24$ & & \\
\hline & & size & $50 \%$ & $60 \%$ & $70 \%$ & $80 \%$ & $100 \%$ & $50 \%$ & $60 \%$ & $70 \%$ & $80 \%$ & $100 \%$ & $50 \%$ & $60 \%$ & $70 \%$ & $80 \%$ & $100 \%$ \\
\hline & & result & 8308 & 8106 & 8073 & 7966 & 7966 & 9035 & 8621 & 8459 & 8284 & 8284 & 8572 & 8168 & 7807 & 7807 & 7366 \\
\hline & & NB & & & $(r=22$ & & & & & $(r=17$ & & & & & $(r=22$ & & \\
\hline & & size & $50 \%$ & $60 \%$ & $70 \%$ & $80 \%$ & $100 \%$ & $50 \%$ & $60 \%$ & $70 \%$ & $80 \%$ & $100 \%$ & $50 \%$ & $60 \%$ & $70 \%$ & $80 \%$ & $100 \%$ \\
\hline & 11 & result & 6642 & 6194 & 6251 & 6247 & 6135 & 8108 & 7015 & 6972 & 6872 & 6349 & 6795 & 6849 & 6361 & 6361 & 6361 \\
\hline & & NB & & & $(r=25$ & & & & & $(r=18$ & & & & & $(r=21$ & & \\
\hline & & size & $50 \%$ & $60 \%$ & $70 \%$ & $80 \%$ & $100 \%$ & $50 \%$ & $60 \%$ & $70 \%$ & $80 \%$ & $100 \%$ & $50 \%$ & $60 \%$ & $70 \%$ & $80 \%$ & $100 \%$ \\
\hline & & result & 7322 & 7215 & 7175 & 7167 & 7167 & 8832 & 7927 & 8066 & 7614 & 7597 & 8214 & 7847 & 7847 & 7797 & 7366 \\
\hline & & NB & & & $(r=28$ & & & & & $(r=20$ & & & & & $(r=23$ & & \\
\hline & & size & $50 \%$ & $60 \%$ & $70 \%$ & $80 \%$ & $100 \%$ & $50 \%$ & $60 \%$ & $70 \%$ & $80 \%$ & $100 \%$ & $50 \%$ & $60 \%$ & $70 \%$ & $80 \%$ & $100 \%$ \\
\hline & 7 & result & 8137 & 7704 & 7428 & 7382 & 7272 & 8399 & 7854 & 8060 & 7952 & 7543 & 8674 & 8513 & 8384 & 8279 & 7864 \\
\hline & & NB & & & $(r=23$ & & & & & $(r=16$ & & & & & $(r=17$ & & \\
\hline & & size & $50 \%$ & $60 \%$ & $70 \%$ & $80 \%$ & $100 \%$ & $50 \%$ & $60 \%$ & $70 \%$ & $80 \%$ & $100 \%$ & $50 \%$ & $60 \%$ & $70 \%$ & $80 \%$ & $100 \%$ \\
\hline & & result & 8484 & 8443 & 8443 & 8242 & 8137 & 9912 & 9332 & 8708 & 8708 & 8664 & 10351 & 9891 & 9486 & 9342 & 8795 \\
\hline & & NB & & & $r=25$ & & & & & $(r=14$ & & & & & $r=19$ & & \\
\hline & & size & $50 \%$ & $60 \%$ & $70 \%$ & $80 \%$ & $100 \%$ & $50 \%$ & $60 \%$ & $70 \%$ & $80 \%$ & $100 \%$ & $50 \%$ & $60 \%$ & $70 \%$ & $80 \%$ & $100 \%$ \\
\hline kroC100 & 9 & result & 7545 & 7205 & 7155 & 6599 & 6349 & - & 8195 & 7921 & 7384 & 6825 & 8219 & 7819 & 7146 & 7325 & 7317 \\
\hline & & NB & & & $(r=18$ & & & & & $(r=13$ & & & & & $(r=30$ & & \\
\hline & & size & $50 \%$ & $60 \%$ & $70 \%$ & $80 \%$ & $100 \%$ & $50 \%$ & $60 \%$ & $70 \%$ & $80 \%$ & $100 \%$ & $50 \%$ & $60 \%$ & $70 \%$ & $80 \%$ & $100 \%$ \\
\hline & & result & 8372 & 7952 & 7617 & 7501 & 7206 & - & 9343 & 8607 & 8342 & 7612 & 8058 & 7981 & 7708 & 7708 & 7708 \\
\hline & & NB & & & $(r=19$ & & & & & $(r=24$ & & & & & $(r=26$ & & \\
\hline & & $\begin{array}{l}\text { size } \\
\end{array}$ & $50 \%$ & $60 \%$ & $70 \%$ & $80 \%$ & $100 \%$ & $50 \%$ & $60 \%$ & $70 \%$ & $80 \%$ & $100 \%$ & $50 \%$ & $60 \%$ & $70 \%$ & $80 \%$ & $100 \%$ \\
\hline & 11 & result & 9095 & 8267 & 7934 & 7219 & 5851 & - & - & 8621 & 8316 & 6422 & - & 9027 & 8969 & 8626 & 6515 \\
\hline & & NB & & & $(r=12$ & & & & & $(r=29$ & & & & & $(r=34$ & & \\
\hline & & size & $50 \%$ & $60 \%$ & $70 \%$ & $80 \%$ & $100 \%$ & $50 \%$ & $60 \%$ & $70 \%$ & $80 \%$ & $100 \%$ & $50 \%$ & $60 \%$ & $70 \%$ & $80 \%$ & $100 \%$ \\
\hline & & result & - & - & - & 10377 & 6705 & - & - & 9867 & 9867 & 7884 & 7399 & 7392 & 7392 & 7392 & 7366 \\
\hline & & NB & & & $(r=25$ & & & & & $(r=14$ & & & & & $(r=17$ & & \\
\hline & & size & $50 \%$ & $60 \%$ & $70 \%$ & $80 \%$ & $100 \%$ & $50 \%$ & $60 \%$ & $70 \%$ & $80 \%$ & $100 \%$ & $50 \%$ & $60 \%$ & $70 \%$ & $80 \%$ & $100 \%$ \\
\hline & 7 & result & 9095 & 8267 & 7934 & 7219 & 6866 & - & - & 8621 & 8316 & 8032 & - & 9027 & 8969 & 8626 & 8030 \\
\hline & & NB & & & $(r=12$ & & & & & $r=19$ & & & & & $(r=16$ & & \\
\hline & & size & $50 \%$ & $60 \%$ & $70 \%$ & $80 \%$ & $100 \%$ & $50 \%$ & $60 \%$ & $70 \%$ & $80 \%$ & $100 \%$ & $50 \%$ & $60 \%$ & $70 \%$ & $80 \%$ & $100 \%$ \\
\hline & & result & - & - & - & 10377 & 8647 & - & - & 9867 & 9867 & 9084 & 10675 & 9671 & 9355 & 9355 & 9221 \\
\hline & & NB & & & $(r=16$ & & & & & $(r=21$ & & & & & $(r=15$ & & \\
\hline & & size & $50 \%$ & $60 \%$ & $70 \%$ & $80 \%$ & $100 \%$ & $50 \%$ & $60 \%$ & $70 \%$ & $80 \%$ & $100 \%$ & $50 \%$ & $60 \%$ & $70 \%$ & $80 \%$ & $100 \%$ \\
\hline kroD100 & 9 & result & - & 8415 & 7376 & 6474 & 6474 & 7805 & 7386 & 7070 & 7011 & 6846 & 9585 & 8211 & 7876 & 7876 & 7778 \\
\hline & & NB & & & $(r=16$ & & & & & $(r=12$ & & & & & $r=16$ & & \\
\hline & & size & $50 \%$ & $60 \%$ & $70 \%$ & $80 \%$ & $100 \%$ & $50 \%$ & $60 \%$ & $70 \%$ & $80 \%$ & $100 \%$ & $50 \%$ & $60 \%$ & $70 \%$ & $80 \%$ & $100 \%$ \\
\hline & & result & - & 9104 & 7756 & 7593 & 7176- & 9712 & 9004 & 8594 & 7538 & - & 9587 & 8506 & 8506 & 7929 & 7924 \\
\hline & & NB & & & $(r=19$ & & & & & $(r=19$ & & & & & $(r=21$ & & \\
\hline & & size & $50 \%$ & $60 \%$ & $70 \%$ & $80 \%$ & $100 \%$ & $50 \%$ & $60 \%$ & $70 \%$ & $80 \%$ & $100 \%$ & $50 \%$ & $60 \%$ & $70 \%$ & $80 \%$ & $100 \%$ \\
\hline & 11 & result & 7478 & 6761 & 6145 & 5686 & 5525 & 7245 & 6754 & 6561 & 6076 & 6076 & 7681 & 7004 & 6857 & 6465 & 6026 \\
\hline & & NB & & & $(r=15$ & & & & & $(r=15$ & & & & & $(r=16$ & & \\
\hline & & size & $50 \%$ & $60 \%$ & $70 \%$ & $80 \%$ & $100 \%$ & $50 \%$ & $60 \%$ & $70 \%$ & $80 \%$ & $100 \%$ & $50 \%$ & $60 \%$ & $70 \%$ & $80 \%$ & $100 \%$ \\
\hline & & result & - & 7629 & 7404 & 7199 & 6890 & 9585 & 8211 & 7876 & 7876 & 7517 & 954 & 8701 & 8165 & 7279 & 7237 \\
\hline & & NB & & & $(r=34$ & & & & & $(r=350$ & & & & & $(r=19$ & & \\
\hline & & size & $50 \%$ & $60 \%$ & $70 \%$ & $80 \%$ & $100 \%$ & $50 \%$ & $60 \%$ & $70 \%$ & $80 \%$ & $100 \%$ & $50 \%$ & $60 \%$ & $70 \%$ & $80 \%$ & $100 \%$ \\
\hline & 7 & result & 10181 & 9762 & 9762 & 9546 & 9220 & 9931 & 10282 & 9567 & 9542 & 542 & 10673 & 10788 & 10470 & 10611 & 10226 \\
\hline & & NB & & & $(r=36$ & & & & & $(r=28$ & & & & & $(r=11$ & & \\
\hline & & size & $50 \%$ & $60 \%$ & $70 \%$ & $80 \%$ & $100 \%$ & $50 \%$ & $60 \%$ & $70 \%$ & $80 \%$ & $100 \%$ & $50 \%$ & $60 \%$ & $70 \%$ & $80 \%$ & $100 \%$ \\
\hline & & $\begin{array}{l}\text { result } \\
\end{array}$ & 10427 & 10427 & 10395 & 10395 & 10264 & 10900 & 10953 & 10386 & 10314 & 10314 & 13393 & 12257 & 12190 & 11424 & 10951 \\
\hline & & NB & & & $(r=32$ & & & & & $r=23$ & & & & & $(r=27$ & & \\
\hline & & size & $50 \%$ & $60 \%$ & $70 \%$ & $80 \%$ & $100 \%$ & $50 \%$ & $60 \%$ & $70 \%$ & $80 \%$ & $100 \%$ & $50 \%$ & $60 \%$ & $70 \%$ & $80 \%$ & $100 \%$ \\
\hline kroA150 & 9 & result & 8487 & 8487 & 8487 & 8033 & 8106 & 10303 & 10214 & 9850 & 9935 & 9339 & 10501 & 10655 & 10092 & 10172 & 10069 \\
\hline & & NB & & & $(r=36$ & & & & & $(r=27$ & & & & & $r=18$ & & \\
\hline & & size & $50 \%$ & $60 \%$ & $70 \%$ & $80 \%$ & $100 \%$ & $50 \%$ & $60 \%$ & $70 \%$ & $80 \%$ & $100 \%$ & $50 \%$ & $60 \%$ & $70 \%$ & $80 \%$ & $100 \%$ \\
\hline & & result & 10427 & 10800 & 10395 & 10366 & 10264 & 10737 & 10783 & 10249 & 10249 & 10249 & 10737 & 10737 & 10249 & 10249 & 10249 \\
\hline & & NB & & & $(r=20$ & & & & & $(r=16$ & & & & & $(r=12$ & & \\
\hline & & size & $50 \%$ & $60 \%$ & $70 \%$ & $80 \%$ & $100 \%$ & $50 \%$ & $60 \%$ & $70 \%$ & $80 \%$ & $100 \%$ & $50 \%$ & $60 \%$ & $70 \%$ & $80 \%$ & $100 \%$ \\
\hline & 11 & $\begin{array}{l}\text { result } \\
\text { res }\end{array}$ & 8366 & 7562 & 7562 & 7805 & 7408 & 10181 & 9149 & 8822 & 8624 & 7967 & - & 11735 & 9918 & 9535 & 8671 \\
\hline & & NB & & & $(r=20$ & & & & & $\left(r=28^{\prime}\right.$ & & & & & $(r=18$ & & \\
\hline & & size & $50 \%$ & $60 \%$ & $70 \%$ & $80 \%$ & $100 \%$ & $50 \%$ & $60 \%$ & $70 \%$ & $80 \%$ & $100 \%$ & $50 \%$ & $60 \%$ & $70 \%$ & $80 \%$ & $100 \%$ \\
\hline & & result & 9609 & 8955 & 9282 & 9245 & 8980 & 967 & 9395 & 9454 & 9547 & 9547 & 9670 & 9571 & 8845 & 8845 & 8845 \\
\hline
\end{tabular}


Table-7: Results under the restriction of group coverage cost $\mathrm{NC}(\mathrm{r} / 3)$

\begin{tabular}{|c|c|c|c|c|c|c|c|c|}
\hline Instance & $\mathrm{NC}$ & \multicolumn{7}{|c|}{ Result } \\
\hline \multirow{6}{*}{ berlin52 } & \multirow[b]{2}{*}{7} & NB & $8(r=982)$ & $9(r=1186)$ & $10(r=1124)$ & $11(r=1125)$ & $12(r=1192)$ & $13(r=1315)$ \\
\hline & & Best cost & 1790 & 1919 & 2161 & 2112 & 2371 & 2529 \\
\hline & \multirow[b]{2}{*}{9} & NB & $6(r=960)$ & $7(r=1082)$ & $8(r=982)$ & $9(r=1125)$ & $10(r=1124)$ & $11(r=1125)$ \\
\hline & & Best cost & 1546 & 1487 & 1455 & 1929 & 2181 & 2070 \\
\hline & \multirow[b]{2}{*}{11} & NB & $5(r=780)$ & $6(r=955)$ & $7(r=1082)$ & $8(r=982)$ & $9(r=955)$ & $10(r=1124)$ \\
\hline & & Best cost & 1923 & 1559 & 1487 & 1463 & 1839 & 2168 \\
\hline \multirow{6}{*}{ st70 } & \multirow[b]{2}{*}{7} & NB & $\mathbf{1 1}(r=82)$ & $12(r=72)$ & $13(r=52)$ & $14(r=56)$ & $15(r=54)$ & $16(r=62)$ \\
\hline & & Best cost & 124 & 155 & 155 & 149 & 172 & 198 \\
\hline & \multirow[b]{2}{*}{9} & NB & $9(r=72)$ & $10(r=57)$ & $11(r=82)$ & $12(r=72)$ & $13(r=49)$ & $14(r=56)$ \\
\hline & & Best cost & 141 & 118 & 123 & 133 & 124 & 154 \\
\hline & \multirow[b]{2}{*}{11} & NB & $7(r=84)$ & $8(r=51)$ & $\mathbf{9}(r=52)$ & $10(r=82)$ & $11(r=72)$ & $12(r=52)$ \\
\hline & & Best cost & 111 & 105 & 95 & 107 & 121 & 122 \\
\hline \multirow{6}{*}{ eil76 } & \multirow[b]{2}{*}{7} & NB & $10(r=60)$ & $\mathbf{1 1}(r=33)$ & $12(r=34)$ & $13(r=43)$ & $14(r=33)$ & $15(r=27)$ \\
\hline & & Best cost & 208 & 202 & 227 & 235 & 240 & 252 \\
\hline & \multirow[b]{2}{*}{9} & NB & $8(r=34)$ & $9(r=45)$ & $10(r=43)$ & $11(r=50)$ & $12(r=58)$ & $13(r=32)$ \\
\hline & & Best cost & 162 & 203 & 191 & 188 & 226 & 235 \\
\hline & \multirow[b]{2}{*}{11} & NB & $7(r=43)$ & $8(r=39)$ & $9(r=43)$ & $10(r=42)$ & $11(r=46)$ & $12(r=50)$ \\
\hline & & Best cost & 136 & 178 & 197 & 191 & 186 & 224 \\
\hline \multirow{6}{*}{ kroA100 } & \multirow[b]{2}{*}{7} & NB & $\mathbf{1 5}(r=1875)$ & $16(r=947)$ & $17(r=2852)$ & $18(r=2160)$ & $19(r=2352)$ & $20(r=1520)$ \\
\hline & & Best cost & 8191 & 8191 & 8261 & 8664 & 8880 & 9448 \\
\hline & \multirow[b]{2}{*}{9} & NB & $\mathbf{1 2}(r=1976)$ & $13(r=2569)$ & $14(r=2560)$ & $15(r=1449)$ & $16(r=2426)$ & $17(r=2267)$ \\
\hline & & Best cost & 7170 & 7333 & 7759 & 8565 & 8032 & 8046 \\
\hline & \multirow[b]{2}{*}{11} & NB & $\mathbf{1 0}(r=2995)$ & $11(r=2445)$ & $12(r=2052)$ & $13(r=2641)$ & $14(r=2560)$ & $15(r=1835)$ \\
\hline & & Best cost & 6276 & 6966 & 7360 & 7306 & 7375 & 7821 \\
\hline \multirow{6}{*}{ kroB100 } & \multirow[b]{2}{*}{7} & $\mathrm{NB}$ & $\mathbf{1 5}(r=2233)$ & $16(r=2423)$ & $17(r=2532)$ & $18(r=2216)$ & $19(r=1244)$ & $20(r=1519)$ \\
\hline & & Best cost & 8074 & 8421 & 8159 & 8943 & 9511 & 9384 \\
\hline & \multirow[b]{2}{*}{9} & NB & $12(r=1191)$ & $13(r=1468)$ & $\mathbf{1 4}(r=1842)$ & $15(r=2440)$ & $16(r=1961)$ & $17(r=2457)$ \\
\hline & & Best cost & 7919 & 8104 & 7903 & 8031 & 8413 & 8141 \\
\hline & & NB & $\mathbf{1 0}(r=2212)$ & $11(r=1747)$ & $12(r=2281)$ & $13(r=2556)$ & $14(r=1842)$ & $15(r=2192)$ \\
\hline & 11 & Best cost & 6298 & 6811 & 6745 & 7347 & 7494 & 7915 \\
\hline & & NB & $\mathbf{1 5}(r=2835)$ & $16(r=2003)$ & $17(r=2374)$ & $18(r=2359)$ & $19(r=1635)$ & $20(r=1757)$ \\
\hline & 7 & Best cost & 7678 & 8209 & 8212 & 8365 & 8886 & 8958 \\
\hline & & NB & $\mathbf{1 2}(r=2535)$ & $13(r=1478)$ & $14(r=1902)$ & $15(r=1802)$ & $16(r=1316)$ & $17(r=3027)$ \\
\hline kroC100 & 9 & Best cost & 6764 & 7813 & 7270 & 7684 & 8012 & 7997 \\
\hline & & $\mathrm{NB}$ & $10(r=1907)$ & $\mathbf{1 1}(r=2417)$ & $12(r=2662)$ & $13(r=1246)$ & $14(r=2998)$ & $15(r=3440)$ \\
\hline & 11 & Best cost & 6771 & 6489 & 6786 & 7797 & 7325 & 7371 \\
\hline & & NB & $\mathbf{1 5}(r=2508)$ & $16(r=1414)$ & $17(r=1699)$ & $18(r=1197)$ & $19(r=1908)$ & $20(r=1590)$ \\
\hline & 7 & Best cost & 7447 & 8952 & 8988 & 9181 & 9181 & 9203 \\
\hline & & NB & $12(r=1665)$ & $\mathbf{1 3}(r=2140)$ & $14(r=1592)$ & $15(r=1601)$ & $16(r=1282)$ & $17(r=1601)$ \\
\hline kroD100 & 9 & Best cost & 7751 & 7140 & 8028 & 7930 & 8579 & 8053 \\
\hline & & NB & $\mathbf{1 0}(r=1599)$ & $11(r=1950)$ & $12(r=2154)$ & $13(r=1592)$ & $14(r=1592)$ & $15(r=1653)$ \\
\hline & 11 & Best cost & 6032 & 6489 & 6683 & 6927 & 7803 & 7210 \\
\hline & & NB & $22(r=3408)$ & $\mathbf{2 3}(r=3511)$ & $24(r=1915)$ & $25(r=3664)$ & $26(r=2912)$ & $27(r=2892)$ \\
\hline & 7 & Best cost & 7645 & 7252 & & 8051 & 9090 & 8880 \\
\hline & & NB & $\mathbf{1 7}(r=3202)$ & $23(r=2302)$ & $24(r=2773)$ & $25(r=3664)$ & $26(r=2719)$ & $27(r=1876)$ \\
\hline kroA150 & 9 & Best cost & 6577 & 7774 & 6713 & 7548 & 8648 & 10926 \\
\hline & & NB & $15(r=2091)$ & $18(r=1627)$ & $19(r=1240)$ & $20(r=2056)$ & $21(r=2871)$ & $22(r=1826)$ \\
\hline & 11 & Best cost & & & & 8220 & 6438 & 8614 \\
\hline
\end{tabular}


Table-8: Results of the CSPs with fuzzy cost matrices using two proposed approaches (same result)

\begin{tabular}{|c|c|c|c|c|c|c|c|}
\hline Instance & $\mathrm{NC}$ & \multicolumn{6}{|c|}{ Best tour cost found for different NB } \\
\hline \multirow{6}{*}{ berlin52 } & \multirow[b]{2}{*}{7} & $\mathrm{NB}=\mathbf{8}$ & 9 & 10 & 11 & 12 & 13 \\
\hline & & $\begin{array}{c}{[1446.8,1449} \\
1450.4]\end{array}$ & $\begin{array}{c}{[1359.7,1542,} \\
1543.5]\end{array}$ & $\begin{array}{c}{[215.4,2157} \\
2158.7]\end{array}$ & $\begin{array}{c}{[1636.6,1639,} \\
1641.3]\end{array}$ & $\begin{array}{c}{[2276.3,2279,} \\
2282.0]\end{array}$ & $\begin{array}{c}{[2603.8,2607,} \\
2610.5]\end{array}$ \\
\hline & \multirow[b]{2}{*}{9} & $\mathrm{NB}=6$ & 7 & 8 & 9 & 10 & 11 \\
\hline & & $\begin{array}{c}{[958.5,960} \\
961.3]\end{array}$ & $\begin{array}{c}{[1178.8,1180,} \\
1181.6]\end{array}$ & $\begin{array}{c}{[1480.9,1483,} \\
1484.7]\end{array}$ & $\begin{array}{c}{[1534.8,1537} \\
1538.2]\end{array}$ & $\begin{array}{c}{[2154.4,2157,} \\
2158.7]\end{array}$ & $\begin{array}{c}{[1642.4,1645,} \\
1648.5]\end{array}$ \\
\hline & \multirow[b]{2}{*}{11} & $\mathrm{NB}=\mathbf{5}$ & 6 & 7 & 8 & 9 & 10 \\
\hline & & $\begin{array}{c}{[742.1,743} \\
743.7]\end{array}$ & $\begin{array}{c}\text { [951.8,953, } \\
954.9] \\
\end{array}$ & $\begin{array}{c}1105.5,1107 \\
1108.5]\end{array}$ & $\begin{array}{c}{[1480.9,1483} \\
1484.7]\end{array}$ & $\begin{array}{c}{[1540.8,1543,} \\
1544.9]\end{array}$ & $\begin{array}{c}{[2154.4,2157} \\
2158.7]\end{array}$ \\
\hline \multirow{6}{*}{ st70 } & \multirow[b]{2}{*}{7} & $\mathrm{NB}=\mathbf{1 1}$ & 12 & 13 & 14 & 15 & 16 \\
\hline & & $\begin{array}{c}{[181.2,186} \\
188.8]\end{array}$ & $\begin{array}{c}{[199.7,203,} \\
205.2]\end{array}$ & $\begin{array}{c}{[215.0,219,} \\
222.8]\end{array}$ & $\begin{array}{c}{[231.3,235,} \\
239.3]\end{array}$ & $\begin{array}{c}237.3,241, \\
244.3]\end{array}$ & $\begin{array}{c}{[251.8,256,} \\
260.4]\end{array}$ \\
\hline & \multirow[b]{2}{*}{9} & $\mathrm{NB}=\mathbf{8}$ & 9 & 10 & 11 & 12 & 13 \\
\hline & & $\begin{array}{c}{[138.6,140} \\
141.0]\end{array}$ & $\begin{array}{c}{[152.3,155,} \\
156.3]\end{array}$ & $\begin{array}{c}161.6,164, \\
165.8]\end{array}$ & $\begin{array}{c}{[173.4,176,} \\
178.1]\end{array}$ & $\begin{array}{c}178.5,181, \\
184.2]\end{array}$ & $\begin{array}{c}{[189.3,193,} \\
196.4]\end{array}$ \\
\hline & \multirow[b]{2}{*}{11} & $\mathrm{NB}=\mathbf{7}$ & 8 & 9 & 10 & 11 & 12 \\
\hline & & $\begin{array}{c}{[105.4,108} \\
109.5]\end{array}$ & $\begin{array}{c}140.2,143, \\
144.9]\end{array}$ & $\begin{array}{c}161.6,164, \\
165.8]\end{array}$ & $\begin{array}{c}178.2,181, \\
184.2]\end{array}$ & $\begin{array}{c}108.7,111, \\
112.7]\end{array}$ & $\begin{array}{c}{[122.0,125,} \\
127.2]\end{array}$ \\
\hline \multirow{6}{*}{ eil76 } & \multirow[b]{2}{*}{7} & $\mathrm{NB}=11$ & 12 & 13 & 14 & 15 & 16 \\
\hline & & $\begin{array}{c}\text { [113.2,116, } \\
119.1]\end{array}$ & $\begin{array}{c}123.9,126, \\
128.5] \\
\end{array}$ & $\begin{array}{c}135.0,139, \\
141.8] \\
\end{array}$ & $\begin{array}{c}139.9,143, \\
146.5 \\
\end{array}$ & $\begin{array}{c}148.3,152, \\
156.3] \\
\end{array}$ & $\begin{array}{c}153.7,158, \\
161.5] \\
\end{array}$ \\
\hline & \multirow[b]{2}{*}{9} & $\mathrm{NB}=\mathbf{9}$ & 10 & 11 & 12 & 13 & 14 \\
\hline & & $\begin{array}{c}{[87.6,90,} \\
92.1]\end{array}$ & $\begin{array}{c}99.7,102, \\
104.4]\end{array}$ & $\begin{array}{c}{[110.1,113,} \\
115.3]\end{array}$ & $\begin{array}{c}122.0,125, \\
127.2]\end{array}$ & $\begin{array}{c}136.4,140, \\
142.7]\end{array}$ & $\begin{array}{c}{[147.4,151,} \\
153.8] \\
\end{array}$ \\
\hline & \multirow[b]{2}{*}{11} & $\mathrm{NB}=7$ & 8 & 9 & 10 & 11 & 12 \\
\hline & & $\begin{array}{c}60.6,62, \\
63.8]\end{array}$ & $\begin{array}{c}59.2,61, \\
62.5]\end{array}$ & $\begin{array}{c}90.1,92, \\
93.5]\end{array}$ & $\begin{array}{c}105.9,108, \\
109.7]\end{array}$ & $\begin{array}{c}108.7,111, \\
112.7] \\
\end{array}$ & $\begin{array}{c}122.0,125, \\
127.2]\end{array}$ \\
\hline \multirow{6}{*}{ kroA100 } & \multirow[b]{2}{*}{7} & $\mathrm{NB}=15$ & 16 & 17 & 18 & 19 & 20 \\
\hline & & $\begin{array}{c}{[7054.3,7058,} \\
7062.8]\end{array}$ & $\begin{array}{c}{[8034.8,8038,} \\
8041.5]\end{array}$ & $\begin{array}{c}{[8019.2,8023,} \\
8027.5]\end{array}$ & $\begin{array}{c}{[8121.5,8126} \\
8129.7]\end{array}$ & $\begin{array}{c}{[8923.4,8928,} \\
8932.6]\end{array}$ & $\begin{array}{c}{[9350.3,9356,} \\
9360.8]\end{array}$ \\
\hline & \multirow[b]{2}{*}{9} & $\mathrm{NB}=\mathbf{1 2}$ & 13 & 14 & 15 & 16 & 17 \\
\hline & & $\begin{array}{c}6327.6,6331 \\
6333.7]\end{array}$ & $\begin{array}{c}{[6733.3,6736,} \\
6738.3]\end{array}$ & $\begin{array}{c}{[7611.5,7615,} \\
7618.9]\end{array}$ & $\begin{array}{c}{[7716.7,7721} \\
7724.5]\end{array}$ & $\begin{array}{c}{[8253.1,8257,} \\
8260.8]\end{array}$ & $\begin{array}{c}{[7869.0,7873,} \\
7877.1]\end{array}$ \\
\hline & \multirow[b]{2}{*}{11} & $\mathrm{NB}=\mathbf{1 0}$ & 11 & 12 & 13 & 14 & 15 \\
\hline & & $\begin{array}{c}5662.9,5665 \\
5667.5] \\
\end{array}$ & $\begin{array}{c}{[6346.9,6350,} \\
6352.0]\end{array}$ & $\begin{array}{c}{[6468.7,6472,} \\
6475.1]\end{array}$ & $\begin{array}{c}{[6885.9,6889} \\
6812.1]\end{array}$ & $\begin{array}{c}{[7611.5,7615} \\
7618.9]\end{array}$ & $\begin{array}{c}{[7835.2,7839,} \\
7842.0]\end{array}$ \\
\hline \multirow{6}{*}{ kroB100 } & \multirow[b]{2}{*}{7} & $\mathrm{NB}=15$ & 16 & 17 & 18 & 19 & 20 \\
\hline & & $\begin{array}{c}7210.2,7214 \\
7217.0]\end{array}$ & $\begin{array}{c}8148.1,8152, \\
8156.3]\end{array}$ & $\begin{array}{c}8049.2,8055, \\
8059.6]\end{array}$ & $\begin{array}{c}8725.6,8730, \\
8735.2]\end{array}$ & $\begin{array}{c}{[8681.5,8686,} \\
8690.6]\end{array}$ & $\begin{array}{c}{[9311.4,9315} \\
9318.5]\end{array}$ \\
\hline & \multirow[b]{2}{*}{9} & $\mathrm{NB}=\mathbf{1 2}$ & 13 & 14 & 15 & 16 & 17 \\
\hline & & $\begin{array}{c}{[6523.9,6527} \\
6530.2]\end{array}$ & $\begin{array}{c}{[7136.1,7139} \\
7142.1]\end{array}$ & $\begin{array}{c}{[7411.1,7415,} \\
7418.4]\end{array}$ & $\begin{array}{c}{[7669.8,7674} \\
7678.4]\end{array}$ & $\begin{array}{c}{[8266.5,8271} \\
8275.3]\end{array}$ & $\begin{array}{c}{[8007.7,8012,} \\
8015.2]\end{array}$ \\
\hline & \multirow[b]{2}{*}{11} & $\mathrm{NB}=\mathbf{1 0}$ & 11 & 12 & 13 & 14 & 15 \\
\hline & & $\begin{array}{c}5808.8,5812, \\
5814.7]\end{array}$ & $\begin{array}{c}{[6397.7,6400,} \\
6402.4]\end{array}$ & $\begin{array}{c}{[6537.5,6541,} \\
6543.4]\end{array}$ & $\begin{array}{c}6891.2,6895, \\
6899.2]\end{array}$ & $\begin{array}{c}{[7411.1,7415} \\
7418.4]\end{array}$ & $\begin{array}{c}{[7688.0,7691,} \\
7695.4]\end{array}$ \\
\hline \multirow{6}{*}{ kroC100 } & \multirow[b]{2}{*}{7} & $\mathrm{NB}=\mathbf{1 5}$ & 16 & 17 & 18 & 19 & 20 \\
\hline & & $\begin{array}{c}7335.8,7340 \\
7344.5] \\
\end{array}$ & $\begin{array}{c}{[7811.9,7818,} \\
7820.4]\end{array}$ & $\begin{array}{c}{[7961.8,7965} \\
7974.9]\end{array}$ & $\begin{array}{c}{[8160.1,8165} \\
8170.0]\end{array}$ & $\begin{array}{c}{[8804.9,8810,} \\
8815.3]\end{array}$ & $\begin{array}{c}{[8850.7,8856,} \\
8860.7]\end{array}$ \\
\hline & \multirow[b]{2}{*}{9} & $\mathrm{NB}=\mathbf{1 2}$ & 13 & 14 & 15 & 16 & 17 \\
\hline & & $\begin{array}{c}{[6558.7,6562,} \\
6564.2] \\
\end{array}$ & $\begin{array}{c}{[6659.3,6663,} \\
6666.4]\end{array}$ & $\begin{array}{c}{[7051.8,7055} \\
7058.6]\end{array}$ & $\begin{array}{c}{[6915.4,6919} \\
6922.5]\end{array}$ & $\begin{array}{c}{[7797.2,7801,} \\
7805.0]\end{array}$ & $\begin{array}{c}{[7948.1,7952,} \\
7956.7]\end{array}$ \\
\hline & \multirow[b]{2}{*}{11} & $\mathrm{NB}=\mathbf{1 0}$ & 11 & 12 & 13 & 14 & 15 \\
\hline & & $\begin{array}{c}{[5659.6,5662,} \\
5665.3]\end{array}$ & $\begin{array}{c}{[6379.7,6382,} \\
6384.8]\end{array}$ & $\begin{array}{c}{[6492.3,6496,} \\
6498.6]\end{array}$ & $\begin{array}{c}{[6819.6,6823,} \\
6827.5]\end{array}$ & $\begin{array}{c}{[7051.8,7055,} \\
7058.6]\end{array}$ & $\begin{array}{c}{[7129.5,7134,} \\
7138.6]\end{array}$ \\
\hline
\end{tabular}




\begin{tabular}{|c|c|c|c|c|c|c|c|}
\hline \multicolumn{8}{|c|}{ Table-8:continued } \\
\hline Instance & $\mathrm{NC}$ & \multicolumn{6}{|c|}{ Best tour cost found for different NB } \\
\hline \multirow{6}{*}{ kroD100 } & \multirow[b]{2}{*}{7} & $\mathrm{NB}=15$ & 16 & 17 & 18 & 19 & 20 \\
\hline & & $\begin{array}{c}{[7397.9,7401} \\
7404.9]\end{array}$ & $\begin{array}{c}{[7381.9,7386,} \\
7390.5]\end{array}$ & $\begin{array}{c}{[7678.2,7682} \\
7686.7]\end{array}$ & $\begin{array}{c}{[8110.5,8115} \\
8120.0]\end{array}$ & $\begin{array}{c}{[8935.8,8940,} \\
8945.0]\end{array}$ & $\begin{array}{c}{[9406.0,9410} \\
9415.1]\end{array}$ \\
\hline & \multirow[b]{2}{*}{9} & $\mathrm{NB}=12$ & 13 & 14 & 15 & 16 & 17 \\
\hline & & $\begin{array}{c}6339.7,6343, \\
6346.6]\end{array}$ & $\begin{array}{c}{[6947.2,6950} \\
6953.8]\end{array}$ & $\begin{array}{c}{[7406.6,7410} \\
7413.1]\end{array}$ & $\begin{array}{c}{[6962.4,6965} \\
6968.7]\end{array}$ & $\begin{array}{c}{[7815.3,7819} \\
7822.5]\end{array}$ & $\begin{array}{c}{[7934.9,7939} \\
7941.9]\end{array}$ \\
\hline & \multirow[b]{2}{*}{11} & $\mathrm{NB}=\mathbf{1 0}$ & 11 & 12 & 13 & 14 & 15 \\
\hline & & $\begin{array}{c}5612.3,5615, \\
5617.7]\end{array}$ & $\begin{array}{c}{[5792.4,5795} \\
5797.4]\end{array}$ & $\begin{array}{c}6301.7,6305 \\
6307.8]\end{array}$ & $\begin{array}{c}{[6811.8,6815,} \\
6819.2]\end{array}$ & $\begin{array}{c}{[7267.0,7271} \\
7274.0]\end{array}$ & $\begin{array}{c}{[7399.3,7403} \\
7406.1]\end{array}$ \\
\hline \multirow{6}{*}{ kroE100 } & \multirow[b]{2}{*}{7} & $\mathrm{NB}=\mathbf{1 5}$ & 16 & 17 & 18 & 19 & 20 \\
\hline & & $\begin{array}{c}{[7370.8,7375} \\
7378.4]\end{array}$ & $\begin{array}{c}{[8195.7,8199,} \\
8202.5]\end{array}$ & $\begin{array}{c}{[8068.6,8072,} \\
8075.8]\end{array}$ & $\begin{array}{c}{[8720.5,8726} \\
8730.4]\end{array}$ & $\begin{array}{c}{[8495.4,8501} \\
8506.2]\end{array}$ & $\begin{array}{c}{[9218.9,9224} \\
9229.2]\end{array}$ \\
\hline & \multirow[b]{2}{*}{9} & $\mathrm{NB}=\mathbf{1 2}$ & 13 & 14 & 15 & 16 & 17 \\
\hline & & $\begin{array}{c}6673.1,6676, \\
6679.9]\end{array}$ & $\begin{array}{c}{[7233.7,7238,} \\
7240.9]\end{array}$ & $\begin{array}{c}{[7551.2,7555} \\
7557.9]\end{array}$ & $\begin{array}{c}7605.7,7610 \\
7614.0]\end{array}$ & $\begin{array}{c}8121.8,8126, \\
8130.7]\end{array}$ & $\begin{array}{c}8094.9,8100, \\
8105.0]\end{array}$ \\
\hline & \multirow[b]{2}{*}{11} & $\mathrm{NB}=\mathbf{1 0}$ & 11 & 12 & 13 & 14 & 15 \\
\hline & & $\begin{array}{c}{[6285.1,6287} \\
6289.4]\end{array}$ & $\begin{array}{c}{[6605.2,6608} \\
6611.0]\end{array}$ & $\begin{array}{c}{[6673.7,6677} \\
6680.7]\end{array}$ & $\begin{array}{c}{[6949.8,6953} \\
6955.9]\end{array}$ & $\begin{array}{c}{[7551.2,7555} \\
7557.9]\end{array}$ & $\begin{array}{c}{[7605.7,7610} \\
7614.0]\end{array}$ \\
\hline \multirow{6}{*}{$\operatorname{rd} 100$} & \multirow[b]{2}{*}{7} & $\mathrm{NB}=\mathbf{1 5}$ & 16 & 17 & 18 & 19 & 20 \\
\hline & & $\begin{array}{c}2397.0,2401, \\
2403.1] \\
\end{array}$ & $\begin{array}{c}2590.5,2593 \\
2597.8] \\
\end{array}$ & $\begin{array}{c}2579.6,2583 \\
2586.9] \\
\end{array}$ & $\begin{array}{c}2745.6,2751 \\
2755.3] \\
\end{array}$ & $\begin{array}{c}2843.4,2848, \\
2852.4] \\
\end{array}$ & $\begin{array}{c}2996.7,3003 \\
3008.0] \\
\end{array}$ \\
\hline & \multirow[b]{2}{*}{9} & $\mathrm{NB}=12$ & 13 & 14 & 15 & 16 & 17 \\
\hline & & $\begin{array}{c}{[2222.3,2225} \\
2228.5]\end{array}$ & $\begin{array}{c}{[2187.6,2190,} \\
2193.0]\end{array}$ & $\begin{array}{c}{[2384.1,2388} \\
2392.4]\end{array}$ & $\begin{array}{c}{[2442.6,2446,} \\
2450.2]\end{array}$ & $\begin{array}{c}{[2581.1,2586} \\
2590.3]\end{array}$ & $\begin{array}{c}{[2379.0,2385} \\
2388.8]\end{array}$ \\
\hline & \multirow[b]{2}{*}{11} & $\mathrm{NB}=\mathbf{1 0}$ & 11 & 12 & 13 & 14 & 15 \\
\hline & & $\begin{array}{c}1930.4,1933, \\
1935.8]\end{array}$ & $\begin{array}{c}1979.3,1982, \\
1984.4]\end{array}$ & $\begin{array}{c}2124.1,2127, \\
2130.0]\end{array}$ & $\begin{array}{c}{[2297.8,2302,} \\
2305.5]\end{array}$ & $\begin{array}{c}2384.1,2388, \\
2392.4]\end{array}$ & $\begin{array}{c}2445.1,2448, \\
2452.6]\end{array}$ \\
\hline \multirow{6}{*}{ kroA150 } & \multirow[b]{2}{*}{7} & $\mathrm{NB}=\mathbf{2 2}$ & 23 & 24 & 25 & 26 & 27 \\
\hline & & $\begin{array}{c}9178.8,9184 \\
9190.1]\end{array}$ & $\begin{array}{c}{[9719.5,9725} \\
9730.6]\end{array}$ & $\begin{array}{c}10212.8,10219 \\
10224.7]\end{array}$ & $\begin{array}{c}10497.3,10504 \\
10510.3]\end{array}$ & $\begin{array}{c}{[10292.4,10299} \\
10305.6]\end{array}$ & $\begin{array}{c}{[10974.4,10981} \\
10988.8]\end{array}$ \\
\hline & \multirow[b]{2}{*}{9} & $\mathrm{NB}=\mathbf{1 7}$ & 18 & 19 & 20 & 21 & 22 \\
\hline & & $\begin{array}{c}7965.6,7971 \\
7975.0]\end{array}$ & $\begin{array}{c}\text { [8439.4,8444, } \\
8447.9]\end{array}$ & $\begin{array}{c}8725.4,8730, \\
8735.4]\end{array}$ & $\begin{array}{c}8743.9,8749, \\
8755.0]\end{array}$ & $\begin{array}{c}9361.3,9367, \\
9372.7]\end{array}$ & $\begin{array}{c}9465.7,9471, \\
9476.8]\end{array}$ \\
\hline & \multirow[b]{2}{*}{11} & $\mathrm{NB}=14$ & 15 & 16 & 17 & 18 & 19 \\
\hline & & $\begin{array}{c}7313.9,7318, \\
7320.9]\end{array}$ & $\begin{array}{c}{[7729.0,7732,} \\
7735.6]\end{array}$ & $\begin{array}{c}{[7520.4,7525} \\
7529.3]\end{array}$ & $\begin{array}{c}{[8084.0,8088,} \\
8092.2]\end{array}$ & $\begin{array}{c}{[8614.7,8620,} \\
8625.0]\end{array}$ & $\begin{array}{c}{[8691.4,8696,} \\
8701.1]\end{array}$ \\
\hline \multirow{6}{*}{ kroA200 } & \multirow[b]{2}{*}{7} & $\mathrm{NB}=\mathbf{2 9}$ & 30 & 31 & 32 & 33 & 34 \\
\hline & & $\begin{array}{c}10678.6,10686, \\
10692.6]\end{array}$ & $\begin{array}{c}11095.3,11102, \\
11109.9]\end{array}$ & $\begin{array}{c}11240.2,11247, \\
11254.5]\end{array}$ & $\begin{array}{c}11400.6,11408, \\
11414.8]\end{array}$ & $\begin{array}{c}11608.1,11616, \\
11624.3]\end{array}$ & $\begin{array}{c}11755.1,11765, \\
11774.4]\end{array}$ \\
\hline & \multirow[b]{2}{*}{9} & $\mathrm{NB}=\mathbf{2 3}$ & 24 & 25 & 26 & 27 & 28 \\
\hline & & $\begin{array}{c}{[9245.4,9252,} \\
9258.2]\end{array}$ & $\begin{array}{l}{[9775.0,9720,} \\
9726.5]\end{array}$ & $\begin{array}{c}\text { [9810.7,9818, } \\
9824]\end{array}$ & $\begin{array}{c}{[10340.3,10346,} \\
10352.3]\end{array}$ & $\begin{array}{c}{[10249,10256,} \\
10262.3]\end{array}$ & $\begin{array}{c}{[10505.4,10512,} \\
10520.1]\end{array}$ \\
\hline & \multirow[b]{2}{*}{11} & $\mathrm{NB}=\mathbf{1 9}$ & 20 & 21 & 22 & 23 & 24 \\
\hline & & $\begin{array}{c}{[8509.9,8515} \\
8519.2]\end{array}$ & $\begin{array}{c}{[8669.7,8676,} \\
8681.3]\end{array}$ & $\begin{array}{c}{[8928.5,8934,} \\
8937.2]\end{array}$ & $\begin{array}{c}{[9381.8,9388,} \\
9392.6]\end{array}$ & $\begin{array}{c}{[9535.5,9542,} \\
9547]\end{array}$ & $\begin{array}{c}{[9545.5,9552,} \\
9557]\end{array}$ \\
\hline
\end{tabular}


Table-9: Results of the CSPs with rough cost matrices using two proposed approaches (same result)

\begin{tabular}{|c|c|c|c|c|c|c|c|}
\hline Instance & $\mathrm{NC}$ & \multicolumn{6}{|c|}{ Best tour cost found for different NB } \\
\hline \multirow{6}{*}{ berlin 52} & \multirow[b]{2}{*}{7} & $\mathrm{NB}=\mathbf{8}$ & 9 & 10 & 11 & 12 & 13 \\
\hline & & $\begin{array}{c}{[1446,1462.5} \\
1422,1482.4]\end{array}$ & $\begin{array}{c}{[1547,1559.8} \\
1516.3,1585.5]\end{array}$ & $\begin{array}{c}{[2116,2141.6,} \\
2090,2164.6]\end{array}$ & $\begin{array}{c}{[1639,1661.6,} \\
1604.4,1694.4]\end{array}$ & $\begin{array}{c}{[2344,2370.4} \\
2316.1,2400.1]\end{array}$ & $\begin{array}{c}{[2709,2742.9,} \\
2671.9,2778.2]\end{array}$ \\
\hline & \multirow[b]{2}{*}{9} & $\mathrm{NB}=6$ & 7 & 8 & 9 & 10 & 11 \\
\hline & & $\begin{array}{c}{[909,923.6} \\
889.3,934.4]\end{array}$ & $\begin{array}{c}{[1181,1196.8,} \\
1165.2,1210.2]\end{array}$ & $\begin{array}{c}{[1483,1505.5,} \\
1456.8,1524.5]\end{array}$ & $\begin{array}{c}{[1537,1560.3,} \\
1509.7,1586.3]\end{array}$ & $\begin{array}{c}2116,2141.6 \\
2090.2164 .6]\end{array}$ & $\begin{array}{c}1645,1665.6, \\
1615.9,1697]\end{array}$ \\
\hline & \multirow[b]{2}{*}{11} & $\mathrm{NB}=\mathbf{5}$ & 6 & 7 & 8 & 9 & 10 \\
\hline & & $\begin{array}{c}{[743,751.8} \\
729.9,764.8]\end{array}$ & $\begin{array}{c}{[915,927.5} \\
901.5,938.8]\end{array}$ & $\begin{array}{l}1194,1207.4 \\
1178.9,1224]\end{array}$ & $\begin{array}{c}1483,1505.5 \\
1456.8,1524]\end{array}$ & $\begin{array}{c}{[1549,1561.3} \\
1531.9,1579.7]\end{array}$ & $\begin{array}{c}{[2116,2141.6,} \\
2090.2,2164.6]\end{array}$ \\
\hline \multirow{6}{*}{ st70 } & \multirow[b]{2}{*}{7} & $\mathrm{NB}=\mathbf{1 0}$ & 11 & 12 & 13 & 14 & 15 \\
\hline & & $\begin{array}{c}162,178.4, \\
143.6,201.7]\end{array}$ & $\begin{array}{c}{[197,221,} \\
173.5,253.4]\end{array}$ & $\begin{array}{c}{[202,216.4,} \\
178.6,247.5]\end{array}$ & $\begin{array}{c}221,250.1, \\
192.7,286.3]\end{array}$ & $\begin{array}{l}{[234,263.6,} \\
191.8,287]\end{array}$ & $\begin{array}{c}{[244,276,} \\
200.5,306.9]\end{array}$ \\
\hline & \multirow[b]{2}{*}{9} & $\mathrm{NB}=\mathbf{8}$ & 9 & 10 & 11 & 12 & 13 \\
\hline & & $\begin{array}{c}{[138,157.1} \\
, \mathbf{1 2 5 . 9}, 174.5]\end{array}$ & $\begin{array}{c}{[168,189,} \\
144.1,208.2]\end{array}$ & $\begin{array}{c}{[162,178.4,} \\
143.6,201.7]\end{array}$ & $\begin{array}{c}{[200,222.2} \\
, 173.8,248.3]\end{array}$ & $\begin{array}{c}{[206,224.9,} \\
175.9,246.8]\end{array}$ & $\begin{array}{c}{[222,252.6,} \\
192.4,284.5]\end{array}$ \\
\hline & \multirow[b]{2}{*}{11} & $\mathrm{NB}=\mathbf{7}$ & 8 & 9 & 10 & 11 & 12 \\
\hline & & $\begin{array}{c}126,139.9 \\
119.1,152.2]\end{array}$ & $\begin{array}{c}144,159.4, \\
129.3,174.2]\end{array}$ & $\begin{array}{c}161,183.1 \\
140.9,206.3]\end{array}$ & $\begin{array}{c}162,178.4, \\
143.6,201.7]\end{array}$ & $\begin{array}{c}200,222.2, \\
173.8,248.3]\end{array}$ & $\begin{array}{c}210,234.4 \\
197.5,263.5]\end{array}$ \\
\hline \multirow{6}{*}{ eil76 } & \multirow[b]{2}{*}{7} & $\mathrm{NB}=\mathbf{1 1}$ & 12 & 13 & 14 & 15 & 16 \\
\hline & & $\begin{array}{l}{[119,145.6} \\
82.4,172.6]\end{array}$ & $\begin{array}{c}{[125,149.8,} \\
96,173.4]\end{array}$ & $\begin{array}{c}{[142,174,} \\
111.3,204.4]\end{array}$ & $\begin{array}{c}133,170.4, \\
92,210.3]\end{array}$ & $\begin{array}{c}{[152,188.5,} \\
114.2,221.2]\end{array}$ & $\begin{array}{c}{[162,195.5,} \\
120.6,237.5]\end{array}$ \\
\hline & \multirow[b]{2}{*}{9} & $\mathrm{NB}=\mathbf{9}$ & 10 & 11 & 12 & 13 & 14 \\
\hline & & $\begin{array}{c}{[87,97.7} \\
69.3,130.1]\end{array}$ & $\begin{array}{c}{[98,119.4,} \\
71.3,139.6]\end{array}$ & $\begin{array}{l}120,135.5, \\
92.9,165.5]\end{array}$ & $\begin{array}{c}125,144.4, \\
97,172.6]\end{array}$ & $\begin{array}{c}{[136,163.3} \\
104.1,199.5]\end{array}$ & $\begin{array}{l}140,170.5, \\
100,200.4]\end{array}$ \\
\hline & \multirow[b]{2}{*}{11} & $\mathrm{NB}=\mathbf{7}$ & 8 & 9 & 10 & 11 & 12 \\
\hline & & $\begin{array}{c}67,81.3, \\
48.5,103.9]\end{array}$ & $\begin{array}{c}78,94, \\
58.3,119.6]\end{array}$ & $\begin{array}{c}96,115.5 \\
68.9,136.7]\end{array}$ & $\begin{array}{l}100,127.6, \\
76.2,157.3]\end{array}$ & $\begin{array}{c}117,139.4, \\
86,171.1]\end{array}$ & $\begin{array}{c}125,144.4, \\
97,172.6]\end{array}$ \\
\hline \multirow{6}{*}{ rat99 } & \multirow[b]{2}{*}{7} & $\mathrm{NB}=15$ & 16 & 17 & 18 & 19 & 20 \\
\hline & & $\begin{array}{c}{[385,406.7} \\
354.5,445.3]\end{array}$ & $\begin{array}{c}{[403,431.2} \\
364.1,459.7]\end{array}$ & $\begin{array}{c}{[406,452.5} \\
367.1,484.8]\end{array}$ & $\begin{array}{c}{[426,467,} \\
376.5,518]\end{array}$ & $\begin{array}{c}{[441,479.2,} \\
387.1,529.9]\end{array}$ & $\begin{array}{c}{[450,504.6,} \\
384.5,564.8]\end{array}$ \\
\hline & \multirow[b]{2}{*}{9} & $\mathrm{NB}=11$ & 12 & 13 & 14 & 15 & 16 \\
\hline & & $\begin{array}{c}{[304,327.8,} \\
279.3,351.1]\end{array}$ & $\begin{array}{c}{[325,352.7,} \\
294.5,382.5]\end{array}$ & $\begin{array}{c}{[349,380.5,} \\
320.8,402.1]\end{array}$ & $\begin{array}{c}{[372,403.2,} \\
347.5,431.2]\end{array}$ & $\begin{array}{c}{[370,404.9,} \\
333.9,441.3]\end{array}$ & $\begin{array}{c}{[385,425.3,} \\
346.9,465.2]\end{array}$ \\
\hline & \multirow[b]{2}{*}{11} & $\mathrm{NB}=\mathbf{9}$ & 10 & 11 & 12 & 13 & 14 \\
\hline & & $\begin{array}{c}{[260,276.9,} \\
234.7,290.8]\end{array}$ & $\begin{array}{l}269,293.7, \\
250.1,315]\end{array}$ & $\begin{array}{c}304,327.8 \\
279.3,351.1]\end{array}$ & $\begin{array}{c}{[330,352.5,} \\
306.1,378.2]\end{array}$ & $\begin{array}{c}{[346,379,} \\
316.4,409.8]\end{array}$ & $\begin{array}{c}{[372,403.0,} \\
347.3,431.2]\end{array}$ \\
\hline \multirow{6}{*}{$\operatorname{rd} 100$} & \multirow[b]{2}{*}{7} & $\mathrm{NB}=15$ & 16 & 17 & 18 & 19 & 20 \\
\hline & & $\begin{array}{c}{[2401,2434.2,} \\
2364.3,2473.9]\end{array}$ & $\begin{array}{c}{[2599,2636.5,} \\
2563.6,2686.1]\end{array}$ & $\begin{array}{c}{[2534,2565.3,} \\
2495.7,2604.2]\end{array}$ & $\begin{array}{c}{[2712,2761.6,} \\
2656.8,2809.5]\end{array}$ & $\begin{array}{c}{[2848,2896.6,} \\
2796.2,2940.5]\end{array}$ & $\begin{array}{c}{[2927,3032.8,} \\
2913.4,3071.1]\end{array}$ \\
\hline & \multirow[b]{2}{*}{9} & $\mathrm{NB}=12$ & 13 & 14 & 15 & 16 & 17 \\
\hline & & $\begin{array}{c}{[2161,2189.9,} \\
2128.1,2226.2]\end{array}$ & $\begin{array}{c}{[2190,2215.4,} \\
2157.4,2237.8]\end{array}$ & $\begin{array}{c}{[2428,2459.9,} \\
2376.7,2496.7]\end{array}$ & $\begin{array}{c}{[2512,2546.7,} \\
2471.2,2582.4]\end{array}$ & $\begin{array}{c}{[2633,2665.2,} \\
2607.8,2710.7]\end{array}$ & $\begin{array}{c}{[2640,2686.4,} \\
2607.8,2728.9]\end{array}$ \\
\hline & \multirow[b]{2}{*}{11} & $\mathrm{NB}=\mathbf{1 0}$ & 11 & 12 & 13 & 14 & 15 \\
\hline & & $\begin{array}{c}{[1952,1975.7} \\
1921.3,2005.8]\end{array}$ & $\begin{array}{c}{[2027,2054.8,} \\
1999.1,2084.2]\end{array}$ & $\begin{array}{c}{[2127,2154.8,} \\
1999.1,2084.2]\end{array}$ & $\begin{array}{c}{[2262,2288.6,} \\
2226.8,2323.9]\end{array}$ & $\begin{array}{c}{[2428,2459.9,} \\
2376.7,2496.7]\end{array}$ & $\begin{array}{c}{[2527,2564.1,} \\
2490.6,2606.1]\end{array}$ \\
\hline \multirow{6}{*}{ kroA100 } & \multirow[b]{2}{*}{7} & $\mathrm{NB}=15$ & 16 & 17 & 18 & 19 & 20 \\
\hline & & $\begin{array}{c}{[7291,7327.8} \\
7241.6,7374]\end{array}$ & $\begin{array}{c}{[8038,8077.5,} \\
8006.8,8120.9]\end{array}$ & $\begin{array}{c}8023,8060.6, \\
7985.4,8109.2]\end{array}$ & $\begin{array}{c}{[8199,8236.3,} \\
8171.8,8284.8]\end{array}$ & $\begin{array}{c}{[8996,9035.3,} \\
8958.2,9069.3]\end{array}$ & $\begin{array}{c}{[9356,9387.4,} \\
9298.5,9439.3]\end{array}$ \\
\hline & \multirow[b]{2}{*}{9} & $\mathrm{NB}=\mathbf{1 2}$ & 13 & 14 & 15 & 16 & 17 \\
\hline & & $\begin{array}{l}6331,6357.4, \\
6235,6388.9]\end{array}$ & $\begin{array}{c}{[6736,6756.8,} \\
6697.8,6794.2]\end{array}$ & $\begin{array}{c}{[7684,7722,} \\
7644.7,7759.2]\end{array}$ & $\begin{array}{c}{[7721,7754.2,} \\
7687.1,7797.6]\end{array}$ & $\begin{array}{c}{[8257,8287.5,} \\
8220.9,8327.5]\end{array}$ & $\begin{array}{c}7916,7951, \\
7886.5,7995.6]\end{array}$ \\
\hline & \multirow[b]{2}{*}{11} & $\mathrm{NB}=\mathbf{1 0}$ & 11 & 12 & 13 & 14 & 15 \\
\hline & & $\begin{array}{c}{[5665,5683.9,} \\
5636.6,5708.7]\end{array}$ & $\begin{array}{c}{[6350,6375.7} \\
6321.1,6401]\end{array}$ & $\begin{array}{c}{[6472,6506.8,} \\
6441.5,6534.3]\end{array}$ & $\begin{array}{c}{[6869,6905.3,} \\
6837.1,6942.6]\end{array}$ & $\begin{array}{c}7684,7722, \\
7644.7,7755.2]\end{array}$ & $\begin{array}{c}{[7614,7645.9,} \\
7570.3,7697.2]\end{array}$ \\
\hline
\end{tabular}


Table-9:continued

\begin{tabular}{|c|c|c|c|c|c|c|c|}
\hline Instance & $\mathrm{NC}$ & \multicolumn{6}{|c|}{ Best tour cost found for different NB } \\
\hline \multirow{6}{*}{ kroB100 } & \multirow[b]{2}{*}{7} & $\mathrm{NB}=15$ & 16 & 17 & 18 & 19 & 20 \\
\hline & & $\begin{array}{c}\text { [7214,7235.2, } \\
7182.9,7291.4]\end{array}$ & $\begin{array}{c}{[8152,8185.1,} \\
8109.2,8222.7]\end{array}$ & $\begin{array}{c}{[8056,8085.4,} \\
8014.7,8125.1]\end{array}$ & $\begin{array}{c}{[8692,8734.1,} \\
8649.2,8773.7]\end{array}$ & $\begin{array}{c}8686,8730.8, \\
8636.5,8782.5]\end{array}$ & $\begin{array}{c}{[9135,9176.4,} \\
9090.7,9229.4]\end{array}$ \\
\hline & \multirow[b]{2}{*}{9} & $\mathrm{NB}=12$ & 13 & 14 & 15 & 16 & 17 \\
\hline & & $\begin{array}{c}{[6527,6558.8,} \\
6504.3,6589.8]\end{array}$ & $\begin{array}{c}{[7139,7165.4,} \\
7098.3,7200.6]\end{array}$ & $\begin{array}{c}{[7415,7447.7,} \\
7386.2,7483.5]\end{array}$ & $\begin{array}{c}{[7674,7708,} \\
7643,7750.8]\end{array}$ & $\begin{array}{c}{[8271,8300.8,} \\
8222.5,8341.7]\end{array}$ & $\begin{array}{c}{[8135,8173.6,]} \\
8089,8225.4\end{array}$ \\
\hline & \multirow[b]{2}{*}{11} & $\mathrm{NB}=\mathbf{1 0}$ & 11 & 12 & 13 & 14 & 15 \\
\hline & & $\begin{array}{c}{[5779,5800.3,} \\
5744.5,5817.9]\end{array}$ & $\begin{array}{c}{[6400,6420.1,} \\
6366.7,6440.9]\end{array}$ & $\begin{array}{c}{[6514,6540.5,} \\
6481.4,6578.8]\end{array}$ & $\begin{array}{c}{[7247,7276.6,} \\
7201.9,7310.3]\end{array}$ & $\begin{array}{c}{[7415,7447.7,} \\
7386.2,7483.5]\end{array}$ & $\begin{array}{r}{[7691,7720,} \\
7638,7767]\end{array}$ \\
\hline \multirow{6}{*}{ kroD100 } & \multirow[b]{2}{*}{7} & $\mathrm{NB}=15$ & 16 & 17 & 18 & 19 & 20 \\
\hline & & $\begin{array}{c}{[7401,7435.6,} \\
7631.1,7471.8]\end{array}$ & $\begin{array}{c}{[7386,7424.3,} \\
7344.8,7468.9]\end{array}$ & $\begin{array}{c}{[7682,7719,} \\
7639.5,7763.8]\end{array}$ & $\begin{array}{c}{[8115,8159.9,} \\
8063.9,8211.3]\end{array}$ & $\begin{array}{c}{[8920,8956.6,} \\
8875.9,9006.9]\end{array}$ & $\begin{array}{c}{[9284,9321.6,} \\
9236.5,9377.6]\end{array}$ \\
\hline & \multirow[b]{2}{*}{9} & $\mathrm{NB}=12$ & 13 & 14 & 15 & 16 & 17 \\
\hline & & $\begin{array}{c}6343,6364.2, \\
6315.7,6398.4] \\
\end{array}$ & $\begin{array}{l}{[6950,6977.8,} \\
{[6950,6977.8,}\end{array}$ & $\begin{array}{c}7271,7303.4, \\
7238.7,7339.1] \\
\end{array}$ & $\begin{array}{c}6965,7001.7, \\
6927.7,7037.2] \\
\end{array}$ & $\begin{array}{c}7926,7968.4, \\
7894.7,7995.8]\end{array}$ & $\begin{array}{c}7939,7978.9, \\
7890.8,8018.4]\end{array}$ \\
\hline & \multirow[b]{2}{*}{11} & $\mathrm{NB}=\mathbf{1 0}$ & 11 & 12 & 13 & 14 & 15 \\
\hline & & $\begin{array}{c}5615,5633.3, \\
5587.7,5655.5]\end{array}$ & $\begin{array}{c}{[5795,5820.6,} \\
5768.7,5844.6]\end{array}$ & $\begin{array}{c}6305,6324.2, \\
6272.4,6353.7]\end{array}$ & $\begin{array}{c}6768,6793.8, \\
6738.9,6823.1]\end{array}$ & $\begin{array}{c}7271,7303.1, \\
7238.7,7339.1]\end{array}$ & $\begin{array}{c}{[7359,7388.2,} \\
73247424.8]\end{array}$ \\
\hline \multirow{8}{*}{ kroA150 } & \multirow[b]{2}{*}{7} & $\mathrm{NB}=15$ & 16 & 17 & 18 & 19 & 20 \\
\hline & & $\begin{array}{c}{[2401,2434.2} \\
2364.3,2473.9]\end{array}$ & $\begin{array}{c}{[2599,2636.5,} \\
2563.6,2686.1]\end{array}$ & $\begin{array}{c}{[2534,2565.3,} \\
2495.7,2604.2]\end{array}$ & $\begin{array}{c}{[2712,2761.6,} \\
2656.8,2809.5]\end{array}$ & $\begin{array}{c}{[2848,2896.6,} \\
2796.2,2940.5]\end{array}$ & $\begin{array}{c}{[2927,3032.8,} \\
2913.4,3071.1]\end{array}$ \\
\hline & \multirow[b]{2}{*}{7} & $\mathrm{NB}=\mathbf{2 2}$ & 23 & 24 & 25 & 26 & 27 \\
\hline & & $\begin{array}{c}{[9184,9228.3,} \\
9132.6,9294.5]\end{array}$ & $\begin{array}{c}{[9823,9872.4,} \\
9771.2,9931.2]\end{array}$ & $\begin{array}{c}{[10344,10407.1,} \\
10286.7,10460.5]\end{array}$ & $\begin{array}{c}{[10583,10643.5,} \\
10528.8,10702.9]\end{array}$ & $\begin{array}{c}{[10299,10351,} \\
10235.9,10410.3]\end{array}$ & $\begin{array}{c}{[10917,10981.1,} \\
10836.3,11047.5]\end{array}$ \\
\hline & \multirow[b]{2}{*}{9} & $\mathrm{NB}=\mathbf{1 7}$ & 18 & 19 & 20 & 21 & 22 \\
\hline & & $\begin{array}{c}{[7806,7841,} \\
7764.8,7879.9]\end{array}$ & $\begin{array}{l}{[8560,8607.7,} \\
8511.6,8645]\end{array}$ & $\begin{array}{c}{[8695,8735.1,} \\
8649.9,8774.7]\end{array}$ & $\begin{array}{c}{[8749,8798.6,} \\
8702.5,8849.9]\end{array}$ & $\begin{array}{c}9163,9211.1, \\
9093.1,9266.3]\end{array}$ & $\begin{array}{c}{[9471,9531.8,} \\
9416.5,9577.7]\end{array}$ \\
\hline & \multirow[b]{2}{*}{11} & $\mathrm{NB}=14$ & 15 & 16 & 17 & 18 & 19 \\
\hline & & $\begin{array}{c}{[7523,7559.4,} \\
7481.8,7590.9]\end{array}$ & $\begin{array}{c}{[7732,7757.2,} \\
7704.7,7794.7]\end{array}$ & $\begin{array}{c}{[8058,8100.7,} \\
8018.4,8134.7]\end{array}$ & $\begin{array}{c}{[8088,8121.8,} \\
8043.9,8157.9]\end{array}$ & $\begin{array}{c}{[8561,8602.2,} \\
8523.8,8644.5]\end{array}$ & $\begin{array}{c}{[8808,8854.1} \\
8766.1,8897.9]\end{array}$ \\
\hline
\end{tabular}

\section{REFERENCES}

[1] Current John R., Schilling David A.: The Covering Salesman Problem, The Ohio University, Columbus, Ohio 43210.

[2] Campbell A. M., Vandenbussche D., Hermann W.: Routing for Relief Efforts,transporation system Vol. 42, No. 2, May (2008).

[3] Dorigo, M., Gambardella, L.M.: Ant colonies for the traveling salesman problem. Biosystems 43, 73-81 (1997).

[4] Dorigo, M., Di Caro, G.: The ant colony optimization meta-heuristics. In: Corne, D., Dorigo, M., Glover, F. (eds.) New Ideas in Optimization, pp. 11-32. McGraw-Hill, London (1999).

[5] Gerhard R.: TSPLIB-A traveling salesman problem library, ORSA journal of computing 3(4) 376384(1999).

[6] Gendreau M, laporte G, Semet F.: The covering tour problem.Computers \& operation research;4010 8694(1992).

[7] Golden, B.L,Nazi-Azimi, Z., Raghavan,S., Salari,M., Toth,P.: The Generalized Covering Salesman Problem,INFORMS journals on computing ,24(4),534-553(2012).

[8] Hachicha M, Hodgson M., Laporte G, Semet F.: Heuristics for the multi-vehicle covering tour problem.Computers \& Operation Research :27:29-42(2000).

[9] Kergosien Y., Lenté C., Billaut J.: Home health care problem An extended multiple Traveling Salesman Problem Multidisciplinary International Conference on Scheduling : Theory and Applications (MISTA 2009), Dublin, Ireland 10-12 August 2009. 
[10] Khanra A., Maiti M. K., Maiti M.: Profit Maximization of TSP with Uncertain Parameters Through a Hybrid Algorithm, Proceedings of the 4th International Conference on Frontiers in Intelligent Computing: Theory and Applications (FICTA), Advances in Intelligent Systems and Computing Science, DOI10.1007/s40595-017-0099-z, Springer(2016).

[11] Khan I., Maiti M. K.: A novel hybrid algorithm for generalized traveling salesman problems in different environments, Vietnam Journal of Computer Science, DOI: 10.1007/s40595-017-0099-z, Springer(2018).

[12] Khan I., Pal S., Maiti M. K.: A modified particle swarm optimization algorithm for solving traveling salesman problem with imprecise cost matrix, 4th International Conference on Recent Advances in Information Technology (RAIT-2018), DOI: 10.1109/RAIT.2018.8389060.

[13] Khan I., Pal S., Maiti M. K.:A Hybrid PSO-GA Algorithm for Traveling Salesman Problems in Different Environments, International Journal of Uncertainty, Fuzziness and Knowledge-Based Systems, 27(5), 693717 (2019).

[14] Kotenko I.,Saenko I.: Hierarchical fuzzy situational networks for online decision-making: Application to telecommunication systems Computers \& operation research ,39, 2594-2602(2019).

[15] Kumar R.: Blending Roulette Wheel Selection and Rank Selection in Genetic Algorithms,International Journal of Machine Learning and Computing, Vol. 2, No. 4, August(2012).

[16] Lin S, Kernighan B.: An effective heuristics algorithm for travelling salesman problem .Operation Research ;21:498-516(1973).

[17] Labbe M., Laporte G., Martin I., Salzar G.: The ring star problem:polyhedral analysis and exact algorithm.Networks ;43(3):177-89(2004).

[18] Labbe M.,Laporte G.,Martin I.,Salzar G.: Locating median cycles in networks.European Journal of Operations Research ;160:457-70(2005).

[19] Liu B.: Theory and Practice of Uncertain Programming, Physica-Verlag, Heidelberg, (2002).

[20] Liu B., Iwamura K.: A note on chance constrained programming with fuzzy coeffcients,, Fuzzy Sets and Systems 100, 229-233(1998).

[21] Maurya A. K., Kumar N.: Localization Problem In Disaster Management Smartphone Application,International Journal of Advanced Research in Computer Science September-October (2017).

[22] Pandiri V., Singh A., Rossi A.: Two hybrid metaheuristic approaches for the covering salesman problem,Neural Computing and Applications,Springer-Verlag London Ltd., part of Springer Nature (2020).

[23] Pramanik P., Maiti M.K., Maiti M.: Three level partial trade credit with promotional cost sharing, .

[24] Salari ,M., \& Naji-Azimi,Z.: An integer programming -based local search for the covering salesman problem.Computers \& operation research ,39,2594-2602 (2012).

[25] Salari M., Reihaneh M., Sabbagh M.S.: Combining ant colony optimization algorithm and dynamic programming technique for solving the covering salesman problem.Computer \& Industrial Engineering ;83:244$251(2015)$.

[26] Sierksma, G.: Hamiltonicity and the 3-OPT procedure for the travelling salesman problem. Appl. Math. 22(2), 351-358 (2014).

[27] Tripathy S., Tulshyan A., Kar S., Pal T.: A metameric genetic algorithm with new operator for covering salesman problem with full coverage. Int J Control Theory Appl10(7):245-252 (2017).

[28] Ungureanu V.: Traveling Salesman Problem with Transportation,Computer Science Journal of Moldova, vol.14, no.2(41), (2006).

[29] Venkatesh P., Srivastava G., Singh A.: A Multi-start Iterated Local Search Algorithm with Variable Degree of Perturbation for the Covering Salesman Problem,Harmony Search and Nature Inspired Optimization Algorithms,Advances in Intelligent Systems and Computing 741, (2019).

[30] Zadeh L.: Fuzzy sets. Information and Control, 8 338-356 (1965) .

[31] Zang X., Jiang Li., Ratli M., Ding1 B.: A parallel variable neighborhood search for solving covering salesman problem,Springer-Verlag GmbH Germany, part of Springer Nature (2020). 


\section{Supplementary Files}

This is a list of supplementary files associated with this preprint. Click to download.

- Highlight.docx

- declarationofcompetinginterests.docx 